\title{
Supply Chain Coordination under Trade Credit and Quantity Discount with Sales Effort Effects
}

\author{
Zhihong Wang ${ }^{1}{ }^{1}$ and Shaofeng Liu ${ }^{2}$ \\ ${ }^{1}$ Glorious Sun School of Business and Management, Dong Hua University, Shanghai 200051, China \\ ${ }^{2}$ Plymouth Business School, University of Plymouth, Plymouth, Devon PL4 8AA, UK \\ Correspondence should be addressed to Zhihong Wang; lilywzh@dhu.edu.cn
}

Received 3 February 2018; Accepted 28 March 2018; Published 7 May 2018

Academic Editor: Jean Jacques Loiseau

Copyright ( 2018 Zhihong Wang and Shaofeng Liu. This is an open access article distributed under the Creative Commons Attribution License, which permits unrestricted use, distribution, and reproduction in any medium, provided the original work is properly cited.

\begin{abstract}
The purpose of this paper is to investigate the role of trade credit and quantity discount in supply chain coordination when the sales effort effect on market demand is considered. In this paper, we consider a two-echelon supply chain consisting of a single retailer ordering a single product from a single manufacturer. Market demand is stochastic and is influenced by retailer sales effort. We formulate an analytical model based on a single trade credit and find that the single trade credit cannot achieve the perfect coordination of the supply chain. Then, we develop a hybrid quantitative analytical model for supply chain coordination by coherently integrating incentives of trade credit and quantity discount with sales effort effects. The results demonstrate that, providing that the discount rate satisfies certain conditions, the proposed hybrid model combining trade credit and quantity discount will be able to effectively coordinate the supply chain by motivating retailers to exert their sales effort and increase product order quantity. Furthermore, the hybrid quantitative analytical model can provide great flexibility in coordinating the supply chain to achieve an optimal situation through the adjustment of relevant parameters to resolve conflict of interests from different supply chain members. Numerical examples are provided to demonstrate the effectiveness of the hybrid model.
\end{abstract}

\section{Introduction}

Trade credit is a form of delayed payments for the transfer of goods and services in which upstream suppliers allow downstream retailers to settle the payments at the end of the sales period. Trade credit has been referred to as one of the important sources of short-term financing for the firms and could play an important role in firms' growth potential, competitive advantage, and survival [1-3]. In addition, it is also an effective incentive and coordination contract [4-8]. Trade credit is widely used in enterprises of various industries in China, the United States, and Europe [1-3]. Suppliers provide trade credit for downstream retailers, allowing them to postpone payments. For retailers, trade credit can reduce their capital occupation and encourage them to increase order quantity. At the same time, suppliers receive more product wholesale income, so trade credit has been regarded as a way to coordinate the supply chain.
Due to rapid advancements in technologies, this has led to an intensified competition from markets and an ever diversifying set of customer needs, as well as shortening the lifecycle of products in many industries, especially in fashion, electronics, and software [9]. The sales season for such products is very limited. For short-life-cycle products, if trade credit is reached between a supplier and a retailer, the retailer is encouraged to increase the order quantity and the retailer should have the ability to sell quickly in a shorter period. Otherwise, it is easy to cause inventory risk. In many settings, retailer sales effort is important in influencing market demand. Retailers can influence demand by hiring more sales personnel, improving their sales skills, increasing advertising, and so on [10-12]. However, there are relevant costs attached to the retailer's sales effort. By offering trade credit to the retailer, the supplier needs to pay a certain amount of capital cost, but it can enjoy benefits from higher market demand influenced by retailer sales effort. Hence, in 
the face of such conflicts of interests, how to optimize the decision-making and coordinate the supply chain is a very important issue for both the supplier and the retailer.

To understand the role of trade credit in coordinating supply chain while taking into account the effects of retailer sales effort on market demand, we develop a quantitative analysis model based on trade credit. We show that when retailer sales effort influences market demand, trade credit cannot achieve supply chain coordination.

In many cases, the composite mode based on two or more different contracts is often designed to coordinate the supply chain $[8,13,14]$. In this paper, we propose a hybrid analytic model under a composite contract with trade credit and quantity discount. We find that when retailer sales effort influences demand, the composite contract can fully achieve supply chain coordination.

The remainder of the paper is organised as follows. Section 2 provides a review of existing article about trade credit. Section 3 discusses the development and analysis of analytic models under a single trade credit considering sales effort effects on demand. The hybrid analytical model under a composite contract with trade credit and quantity discount is proposed in Section 4, followed by an application example in Section 5. Finally, Section 6 draws conclusions.

\section{Literature Review}

Haley and Higgins [15] firstly studied trade credit in the operation management. Since then, the buyer's inventory policy under given trade credit term has been concerned for a long time. Goyal [16] considered the EOQ model under trade credit. Huang [17] extended Goyal [16] model to twopart terms of trade credit. Teng et al. [18] and Taleizadeh et al. [19] further supplemented the study of Huang [17]. Later, Mahata [20], Soni and Joshi [21], Chen et al. [22], and Wu et al. [23] studied the EOQ or EPQ model for deteriorating items under the two-part trade credit.

Instead of setting trade credit as a given parameter, several articles took trade credit as a decision variable from the vendor's or the supply chain's point of view. Kim et al. [24] and Abad and Jaggi [25] developed a model to find the optimal credit period for the vendor by taking price-sensitive demand into consideration. Zhou et al. [26] determined the supplier's credit policy considering inventory-dependent demand and limited displayed-shelf space. Wang et al. [27] developed the EOQ model to study the supplier's optimal credit period and cycle time for deteriorating items. Tsao [28] built the EPQ model under maintenance, variable setup costs, and trade credits. Pramanik et al. [29] built the EOQ model based on three-level partial trade credit.

However, these above studies did not consider the issue of supply chain coordination. Taking trade credit as a mechanism to coordinate a supply chain, Jaber and Osman [30] may be the first study. They studied how to set order quantity and trade credit to minimize the cost of the whole supply chain under constant demand. Luo [7] and Yang et al. [31] proved that trade credit is a new supply chain incentive mechanism which is not equal to the quantity discount. Luo and
Zhang [32] further explored the role of trade credit in coordinating supply chains in the case of asymmetric information on the buyer's capital cost. Sarmah et al. [33] investigated the issue of supply chain coordination with trade credit in the context of multi-heterogeneous buyers.

Chaharsooghi and Heydari [34] considered the credit period as a mechanism to develop coordination in a multiperiod setting. Arkan and Hejazi [35] extended Chaharsooghi and Heydari [34] model by assuming that lead time and ordering cost are controllable.

Zhong and Zhou [36] developed a performance improving model through trade credit by assuming that a retailer had limited storage space and faced an inventory-dependent end demand. Das et al. [37] developed an integrated production inventory model under trade credit for a constant deteriorating item. Ouyang et al. [38] proposed an integrated inventory model under trade credit with capacity constraint and an order-size dependent payment period. Sarkar et al. [6] studied the multilevel trade credit and single-setup-multipledelivery policy for the coordination of a global sustainable supply chain.

Most previous studies on the role of trade credit in coordinating supply chain failed to consider the newsvendor model which is an important mathematical model for uncertain demand. The following articles investigated the role of the composite mechanism based on trade credit and other traditional coordinating contracts in supply chain coordination for uncertain demand. Lee and Rhee [8] examined relatively early the issue of supply chain coordination based on trade credit and markdown allowance in a newsvendor framework. Zhang et al. [39] proposed a modified quantity discount based on both order quantity and advance payment while considering the manufacturer's risk aversion. Yang et al. [40] proposed a two-period continuous newsvendor model under a two-part trade credit contract and examined the influence of the revenue sharing rates on the optimal early payment time from a coordination perspective. Tsao et al. [41] presented newsvendor models to maximize total profits while taking into account uncertain demand, trade credits, carbon emissions, and the risk of default simultaneously. Cao and $\mathrm{Yu}[42]$ investigated the financing and coordination of an emission-dependent supply chain by trade credit. Heydari et al. [4] and Tsao [5] introduced two-level trade credits into supply chain coordination for uncertain demand. Xiao et al. [14] examined whether revenue sharing, buyback, and trade credit contracts can coordinate a constrained supply chain.

In many settings, retailer sales effort is very important in influencing the market demand, but literature has not adequately addressed retailer's sales effort effect on market demand while exploring the supply chain coordination through trade credit. In this paper, we construct newsvendor models to explore the issue of supply chain coordination under trade credit when the market demand is influenced by retailer sales effort. We also derive the optimal sales effort policy and order quantity policy. And we further present newsvendor models to maximize total profits while considering trade credit, order quantity discount, and market demand with sales effort effects simultaneously and examine 
the effect of quantity discount rates on the retailer's and supplier's policies from a coordination perspective.

\section{A Trade-Credit-Only Model with Sales Effort Effects}

We consider a supply chain with a risk-neutral retailer and a risk-neutral supplier. The retailer purchases a single product from the manufacturer. The manufacturer dominates and first sets trade credit contract. Then, the retailer determines order quantity and sales effort according to contract terms and market situation and pays off all payment at the end of sales period. To focus on the essential model feature, we assume that the manufacturer's production capacity is not limited and can provide all goods for the retailer to meet the demand.

The retailer faces the random market demand. We assume the demand which is not influenced by sales effort be $\delta$ with a cumulative distribution function $F(\delta)$ and a probability density function $f(\delta)$. Let the market demand with sales effort effects be $\delta^{\prime}$ in which demand is stochastic and multiplicative function of retailer sales effort. Specifically, let $\delta^{\prime}$ be given by $e \delta$, where $e$ is the level of retailer's sales effort $[11,12]$. The cost to the retailer of exerting $e$ units of sales effort is $C(e)$ which is increasing, convex, and differentiable in $e$, where $e \geq 1$ and $C(1)=0$. Thus, the marginal effectiveness of sales effort is constant, and the marginal cost of sales effort is increasing.

Notations used are presented as follows:

$q$ : The order quantity of the retailer

$p_{m}$ : The unit product wholesale price provided by manufacturer

$c_{m}$ : The manufacturer's unit product production cost

$p_{r}$ : The retailer's unit product sales price

$c_{r}$ : the retailer's unit product sales cost

$v$ : Salvage value of unit product unsold at the end of the sales period

$t$ : Trade credit period

$i_{m}$ : The manufacturer's unit capital cost rate

$i_{r}$ : The retailer's return on investment

$e$ : The retailer's sales effort level

$\theta$ : The quantity discount ratio

$\prod_{l}^{m}$ : Manufacturer's expected profit

$\prod_{l}^{r}$ : Retailer's expected profit

$\prod_{l}^{s}$ : System expected profit

$l=1,2,3$, respectively, denote the 3 different cases.

To avoid unrealistic and trivial cases, we assume that $p_{m}>$ $c_{m}>v, p_{r}>p_{m}+c_{r}$, and $i_{r}>i_{m}$. In addition, the supplier allows the retailer to delay payment, so term period $t$ meets $t>0$.

In the case of general stochastic market demand, comparing the product market demand $\delta$ and the order quantity $q$, we define the retailer's expected product sales $S(q)=$
$E(\min (q, \delta))=q-\int_{0}^{q} F(\delta) d \delta$ and the expected product residual amount $T(q)=E(q-\delta)^{+}=q-S(q)$. In the case of the market demand affected by the sales effort level, comparing the product market demand $\delta^{\prime}$ and the order quantity $q$, we define the retailer's expected product sales:

$$
S(q, e)=E(\min (q, e \delta))=q-e \int_{0}^{q / e} F(\delta) d \delta .
$$

And the expected product residual amount is

$$
T(q, e)=E(q-e \delta)^{+}=q-S(q, e) .
$$

To help fully expose the benefits of the developed trade credit models, this section will use two scenarios: decentralized and centralized coordination decisions. Literature has extensively discussed how to develop trade credit models without consideration for sales effort level [4, 5, 8, 39-42]. This paper will not repeat the details. However, for comparison purpose, the expected profit functions are built for the retailer, the manufacturer, and the supply chain system under trade credit contract in the case of the general stochastic demand, as follows:

$$
\begin{aligned}
\prod_{1}^{r}(q)= & \left(1+i_{r} t\right)\left(p_{r} S(q)+v T(q)\right)-c_{r} q-p_{m} q \\
= & \left(1+i_{r} t\right)\left(p_{r}-v\right)\left(q-\int_{0}^{q} F(\delta) d \delta\right) \\
& +\left[\left(1+i_{r} t\right) v-c_{r}-p_{m}\right] q, \\
\prod_{1}^{m}(q)= & p_{m} q-\left(1+i_{m} t\right) c_{m} q, \\
\prod_{1}^{s}(q)= & \left(1+i_{r} t\right)\left(p_{r}-v\right)\left(q-\int_{0}^{q} F(\delta) d \delta\right) \\
& +\left(\left(1+i_{r} t\right) v-c_{r}-\left(1+i_{m} t\right) c_{m}\right) q .
\end{aligned}
$$

Thus, for the market demand without sales effort effects, the retailer's optimal order quantity $q_{1}^{r}$ and the supply chain system's optimal order quantity $q_{1}^{s}$ are, respectively, as follows:

$$
\begin{aligned}
& q_{1}^{r}=F^{-1}\left(1-\frac{c_{r}+p_{m}-\left(1+i_{r} t\right) v}{\left(1+i_{r} t\right)\left(p_{r}-v\right)}\right), \\
& q_{1}^{s}=F^{-1}\left(1-\frac{c_{r}+\left(1+i_{m} t\right) c_{m}-\left(1+i_{r} t\right) v}{\left(1+i_{r} t\right)\left(p_{r}-v\right)}\right) .
\end{aligned}
$$

3.1. Decentralized Decision Scenario. In the case of the market demand affected by sales effort, the expected profit functions of retailers and manufacturers under decentralized decision model can be developed as follows:

$$
\begin{aligned}
\prod_{2}^{r}(q, e)= & \left(1+i_{r} t\right)\left(p_{r}-v\right)\left(q-e \int_{0}^{q / e} F(\delta) d \delta\right) \\
& +\left(\left(1+i_{r} t\right) v-c_{r}-p_{m}\right) q-C(e), \\
\prod_{2}^{m}(q, e)= & p_{m} q-\left(1+i_{m} t\right) c_{m} q .
\end{aligned}
$$


Proposition 1. Under decentralized decision scenario with sales effort effect, we obtain the retailer's optimal order quantity as

$$
q_{2}^{r}=e F^{-1}\left(1-\frac{c_{r}+p_{m}-\left(1+i_{r} t\right) v}{\left(1+i_{r} t\right)\left(p_{r}-v\right)}\right) .
$$

And the optimal effort level $e_{2}^{r}$ of the retailer meets

$$
\frac{d C\left(e_{2}^{r}\right)}{d e_{2}^{r}}=\left(1+i_{r} t\right)\left(p_{r}-v\right) R\left(\frac{q}{e_{2}^{r}}\right),
$$

where $R(q)=\int_{0}^{q} \delta d F(\delta)$.

Only when (7) satisfies (8), the retailer is able to achieve the greatest profit. Thus, the optimal order quantity of the retailer is $q_{2}^{r}=e_{2}^{r} q_{1}^{r}$, and then the optimal sales effort level $e_{2}^{r}$ satisfies

$$
\frac{d C\left(e_{2}^{r}\right)}{d e_{2}^{r}}=\left(1+i_{r} t\right)\left(p_{r}-v\right) R\left(q_{1}^{r}\right) .
$$

Proof. See "Appendix A."

Theorem 2. In the trade credit contract, by considering sales effort level, the optimal order quantity of the retailer in the decentralized decision mode is not lower than that of the general stochastic market demand; that is, $q_{2}^{r} \geq q_{1}^{r}$.

Proof. Comparing $q_{1}^{r}=F^{-1}\left(1-\left(c_{r}+p_{m}-\left(1+i_{r} t\right) v\right) /(1+\right.$ $\left.\left.i_{r} t\right)\left(p_{r}-v\right)\right)$ with $q_{2}^{r}=e F^{-1}\left(1-\left(c_{r}+p_{m}-\left(1+i_{r} t\right) v\right) /(1+\right.$ $\left.\left.i_{r} t\right)\left(p_{r}-v\right)\right)$, it is found that $q_{2}^{r}=q_{1}^{r}$ when $e=1$ in $q_{2}^{r}$. Thus, it is not difficult to find that $q_{2}^{r} \geq q_{1}^{r}$ when $e \in[1, \infty)$. At the same time, it can be found that, with the increase of the sales effort, the retailer's order quantity will be also increased.

Theorem 2 shows that improving the sales effort level can increase the retailer's order quantity $\Delta q=q_{2}^{r}-q_{1}^{r}$ because the high level of sales service quality promotes the market demand for retailer's products.

Theorem 3. In the decentralized decision model, the retailer's expected profits $\prod_{2}^{r}(q, e)$ and the manufacturer's expected profits $\prod_{2}^{m}(q, e)$ will increase as the sales effort level e increases. Compared with that when sales effort remains constant $(e=1)$, the retailer will make itself and the manufacturer, respectively, obtain higher profits if it raises the level of sales effort to the optimal level; that is, $\prod_{2}^{r}\left(q_{2}^{r}, e_{2}^{r}\right)>\prod_{2}^{r}\left(q_{1}^{r}, e=1\right), \prod_{2}^{m}\left(q_{2}^{r}, e_{2}^{r}\right)>$ $\prod_{2}^{m}\left(q_{1}^{r}, e=1\right)$.

Proof. (1) Let

$$
\prod_{2}^{r}(q, e)=e\left(1+i_{r} t\right)\left(p_{r}-v\right) R\left(q_{1}^{r}\right)-C(e),
$$

where $q=e q_{1}^{r}$. The first order partial derivative of $e$ for equation $\prod_{2}^{r}(q, e)$ is

$$
\frac{\partial \prod_{2}^{r}(q, e)}{\partial e}=\left(1+i_{r} t\right)\left(p_{r}-v\right) R\left(q_{1}^{r}\right)-\frac{d C(e)}{d e} .
$$

And it is known that $d C\left(e_{2}^{r}\right) / d e_{2}^{r}=\left(1+i_{r} t\right)\left(p_{r}-v\right) R\left(q_{1}^{r}\right)$ from (9). Then, $\partial \prod_{2}^{r}(q, e) / \partial e=d C\left(e_{2}^{r}\right) / d e_{2}^{r}-d C(e) / d e$.

$C^{\prime}(e)$ is monotonically increasing on $e \in\left[1, e_{2}^{r}\right]$ because $d^{2} C(e) / d e^{2}>0$; it can be obtained that $d C(e) / d e \leq d C\left(e_{2}^{r}\right) /$ $d e_{2}^{r}$; that is, $\partial \prod_{2}^{r}(q, e) / \partial e \geq 0$; further it can be obtained that $\prod_{2}^{r}(q, e)$ is an increasing function on $e \in e_{2}^{r}$. With the increase of the retailer's sales effort, the expected return of the retailer is also increasing, but the retailer only allows sales effort to be promoted to the best effort level $e_{2}^{r}$.

It is obtained that $\prod_{2}^{r}(q, e)=\prod_{2}^{r}\left(q_{1}^{r}, e=1\right)$ when the sales effort level remains constant $(e=1)$. Therefore, it is easy to know the following:

$\prod_{2}^{r}\left(q=e_{2}^{r} q_{1}^{r}, e_{2}^{r}\right)>\prod_{2}^{r}\left(q=q_{1}^{r}, e=1\right)$; that is, $\prod_{2}^{r}\left(q_{2}^{r}\right.$, $\left.e_{2}^{r}\right)>\prod_{2}^{r}\left(q_{1}^{r}, e=1\right)$.

(2) Let $\prod_{2}^{m}(q, e)=\left(p_{m}-\left(1+i_{m} t\right) c_{m}\right) e q_{1}^{r}$, and it is obtained that $\partial \prod_{2}^{m}(q, e) / \partial e=\left(p_{m}-\left(1+i_{m} t\right) c_{m}\right) q_{1}^{r}>0$.

Obviously, $\prod_{2}^{m}(q, e)$ is an increasing function on $e \in$ $[1, \infty)$, so the manufacturer wants the retailer to maximize the level of sales effort because the manufacturer does not have to bear the effort cost.

Thus, it can be obtained that $\prod_{2}^{m}\left(q=e_{2}^{r} q_{1}^{r}, e_{2}^{r}\right)>$ $\prod_{2}^{m}\left(q=q_{1}^{r}, e=1\right)$; that is,

$$
\prod_{2}^{m}\left(q_{2}^{r}, e_{2}^{r}\right)>\prod_{2}^{m}\left(q_{1}^{r}, e=1\right) .
$$

3.2. Centralized Decision Scenario. This subsection analyzes the coordination effect of the trade credit contract considering the level of sales effort in the centralized decision mode. In this case, the overall expected profit function of the system is constructed:

$$
\begin{aligned}
\prod_{2}^{s}(q, e)= & \left(1+i_{r} t\right)\left(p_{r}-v\right)\left(q-e \int_{0}^{q / e} F(\delta) d \delta\right) \\
& +\left(\left(1+i_{r} t\right) v-c_{r}-\left(1+i_{m} t\right) c_{m}\right) q \\
& -C(e) .
\end{aligned}
$$

Proposition 4. Under centralized decision scenario with sales effort effect, we obtain the optimal order quantity as

$$
q_{2}^{s}=e F^{-1}\left(1-\frac{c_{r}+\left(1+i_{m} t\right) c_{m}-\left(1+i_{r} t\right) v}{\left(1+i_{r} t\right)\left(p_{r}-v\right)}\right) .
$$

And the optimal sales effort level meets

$$
\frac{d C\left(e_{2}^{s}\right)}{d e_{2}^{s}}=\left(1+i_{r} t\right)\left(p_{r}-v\right) R\left(q_{1}^{s}\right),
$$

where $R\left(q_{1}^{s}\right)=\int_{0}^{q_{1}^{s}} \delta d F(\delta)$.

Proof. See “Appendix B.”

Theorem 5. In the trade credit contract, when sales effort level is considered, the optimal order quantity of the system under the centralized decision mode is not lower than that under the general stochastic market demand; that is, $q_{2}^{s} \geq q_{1}^{s}$.

Proof. Comparing $q_{1}^{s}=F^{-1}\left(1-\left(c_{r}+\left(1+i_{m} t\right) c_{m}-\left(1+i_{r} t\right) v\right) /(1+\right.$ $\left.\left.i_{r} t\right)\left(p_{r}-v\right)\right)$ with $q_{2}^{s}=e F^{-1}\left(1-\left(c_{r}+\left(1+i_{m} t\right) c_{m}-(1+\right.\right.$ $\left.\left.\left.i_{r} t\right) v\right) /\left(1+i_{r} t\right)\left(p_{r}-v\right)\right)$, it is found that $q_{2}^{s}=q_{1}^{s}$ when $e=1$ in $q_{2}^{s}$. Therefore, it is not difficult to find that $q_{2}^{s} \geq q_{1}^{s}$ for $e \in[1, \infty)$.

Theorem 5 shows that the customer demand for the retailer's products will be expanded; furthermore, the retailer will be encouraged to increase its order quantity when sales 
effort level increases. In this way, the system's demand for funds is satisfied by improving the reasonable allocation of the flow of funds in the supply chain system, thereby increasing the system's order quantity.

Theorem 6. In the centralized decision model, the system's expected profit $\prod_{2}^{s}(q, e)$ will increase as the sales effort level $e$ increases. Compared with that when the sales effort remains constant $(e=1)$, system's overall profit would become higher if the retailer raises the level of sales effort to the optimal level $e_{2}^{s}$; that is,

$$
\prod_{2}^{s}\left(q_{2}^{s}, e_{2}^{s}\right)>\prod_{2}^{s}\left(q_{1}^{s}, e=1\right) .
$$

Proof. See “Appendix C.”

\subsection{The Effects of Trade Credit Terms on Decisions and Profits}

Theorem 7. In the trade credit contract, when sales effort is considered, the retailer's optimal effort level $e_{2}^{r}$ and optimal order quantity $q_{2}^{r}$ as well as the supply chain system's optimal effort level $e_{2}^{s}$ and optimal order quantity $q_{2}^{s}$ will increase as the trade credit period $t$ increases.

Proof. See “Appendix D.”

Theorem 8. In the trade credit contract that considers the sales effort level, when the retailer determines the optimal effort level $e_{2}^{r}$, there exists always a trade credit period $\widehat{t}$ such that the retailer's optimal expected profit is $N^{r} . \prod_{2}^{r}\left(q_{2}^{r}, e_{2}^{r}\right)$ is not lower than $N^{r}$ for $t \in[\widehat{t},+\infty)$ and increases with the increase of the trade credit period $t$. When the supply chain system determines the optimal effort level $e_{2}^{s}$, there is always a trade credit term $\tilde{t}$ so that the optimal expected return of the supply chain system is $N^{s}$. $\prod_{2}^{s}\left(q_{2}^{s}, e_{2}^{s}\right)$ is not lower than $N^{s}$ for $t \in[\widetilde{t},+\infty)$ and increases as the trade credit period $t$ increases.

\section{Proof. See “Appendix E."}

Theorem 8 shows that trade credit could encourage the retailer to improve the level of optimal efforts and further stimulate the retailer to increase the quantity of orders. In addition, the benefits of the retailer and the overall supply chain can increase as the trade credit period is longer. These theorems show that the trade credit provided by the manufacturer helps to positively affect the supply chain while considering the retail sales effort level.

\subsection{Comparing Centralized Decision Scenario and Decentralized Decision Scenario}

Theorem 9. In the trade credit contract, with the market demand influenced by sales effort, the optimal sales effort level, optimal order quantity of the retailer, and the system's optimal profit under the decentralized decision mode are lower than those under the centralized decision mode; that is,

$$
\begin{aligned}
& e_{2}^{r}<e_{2}^{s}, \\
& q_{2}^{r}<q_{2}^{s},
\end{aligned}
$$

$$
\prod_{2}^{s}\left(q_{2}^{r}, e_{2}^{r}\right)<\prod_{2}^{s}\left(q_{2}^{s}, e_{2}^{s}\right) .
$$

Proof. See “Appendix F."

Theorem 9 shows that both the manufacturer and the retailer are rational, and their goal is to maximize their own interests, so the game will lead the sales effort level and the order quantity to become distorted; that is, $e_{2}^{r}<e_{2}^{s}$ and $q_{2}^{r}<q_{2}^{s}$. Then, the system's profits also appear to be hurt; that is, $\prod_{2}^{s}\left(q_{2}^{r}, e_{2}^{r}\right)<\prod_{2}^{s}\left(q_{2}^{s}, e_{2}^{s}\right)$.

For the manufacturer, it could only make the decision on the wholesale price of the product and the trade credit term. The number of products offered depends on the retailer's order quantity.

It can be obtained that $\partial \prod_{2}^{m}(q, e) / \partial q=p_{m}-\left(1+i_{m} t\right) c_{m}>$ 0 from (6), and then the expected profit of the manufacturer increases with the increase in the retailer's order quantity. From the retailer's point of view, if the order quantity increases from $q_{2}^{r}$ to $q_{2}^{s}$, the retailer cannot accept that because $q_{2}^{s}$ exceeds its optimal order quantity. However, this case will result in damage to the overall interests of the system, so trade credit contracts that consider sales efforts cannot achieve perfect coordination between the manufacturer and the retailer.

Of course, to persuade the retailer to increase the order quantity, the manufacturer can provide the retailers with quantitative discount contracts to make up for the loss of the retailer due to increasing the order.

\section{A Hybrid Quantitative Model under Trade Credit and Quantity Discount with Sales Effort Effects}

In a quantitative discount mechanism, the manufacturer encourages the retailer to increase the amount of the order by reducing the wholesale price per unit of the product. In this paper, a quantity discount mechanism with a ratio $\theta$ is introduced. The expected profit function of the retailer and the manufacturer under the portfolio coordination contract are, respectively, as follows:

$$
\begin{aligned}
\prod_{3}^{r}(q, e)= & \left(1+i_{r} t\right)\left(p_{r}-v\right)\left(q-e \int_{0}^{q / e} F(\delta) d \delta\right) \\
& +\left(\left(1+i_{r} t\right) v-c_{r}-\theta p_{m}\right) q-C(e), \\
\prod_{3}^{m}(q, e)= & \theta p_{m} q-\left(1+i_{m} t\right) c_{m} .
\end{aligned}
$$

In the combined contract, it is a trade credit contract that takes into account the level of sales effort when $\theta=1$. In this case, both sides can benefit as the sales efforts improve, but the retailer will lack the intrinsic incentive and motivation to improve sales efforts because it has to bear the full cost of effort. However, the manufacturer who does not have to make any effort but to enjoy the benefits of increasing the level 
of sales effort expects the retailer to provide a higher level of sales effort. Therefore, there is a certain conflict of interests between the two sides. When $\theta=0$, the manufacturer's product wholesale price is 0 , and its profit is negative, which is unrealistic. Thus, a reasonable discount ratio needs to satisfy $0<\theta<1$.

Proposition 10. Under decentralized decision scenario, we consider incentive contract integrating trade credit and quantity discount when sales effort influences the market demand. We obtain the optimal order quantity as

$$
q_{3}^{r}=e F^{-1}\left(1-\frac{c_{r}+\theta p_{m}-\left(1+i_{r} t\right) v}{\left(1+i_{r} t\right)\left(p_{r}-v\right)}\right) .
$$

And the optimal sales effort level meets

$$
\frac{d C\left(e_{3}^{r}\right)}{d e_{3}^{r}}=\left(1+i_{r} t\right)\left(p_{r}-v\right) R\left(q_{0}\right),
$$

where

$$
\begin{aligned}
q_{0} & =F^{-1}\left(1-\frac{c_{r}+\theta p_{m}-\left(1+i_{r} t\right) v}{\left(1+i_{r} t\right)\left(p_{r}-v\right)}\right), \\
R\left(q_{0}\right) & =\int_{0}^{q_{0}} \delta d F(\delta) .
\end{aligned}
$$

Proof. See "Appendix G.”

From Proposition 10, the retailer's optimal expected profit is $\prod_{3}^{r}\left(q_{3}^{r}, e_{3}^{r}\right)=e_{3}^{r}\left(1+i_{r} t\right)\left(p_{r}-v\right) R\left(q_{0}\right)-C\left(e_{3}^{r}\right)$, and the optimal expected profit of the manufacturer is

$$
\prod_{3}^{m}\left(q_{3}^{r}, e_{3}^{r c}\right)=\left(\theta p_{m}-\left(1+i_{m} t\right) c_{m}\right) e_{3}^{r} q_{0} .
$$

Theorem 11. Considering the level of sales effort, comparing the hybrid model of the trade credit and quantity discount with the single trade credit contract, the optimal sales effort level $e_{3}^{r}$ of the retailer in the former case is higher than the optimal sales effort level $e_{2}^{r}$ in the latter case; that is, $e_{3}^{r}>e_{2}^{r}$. The optimal order quantity $q_{3}^{r}$ of the retailer in the former case is higher than the optimal order quantity $q_{2}^{r}$ in the latter case; that is, $q_{3}^{r}>q_{2}^{r}$. In addition, the optimal effort level $e_{3}^{r}$ and the optimal order quantity $q_{3}^{r}$ of the retailer increase with the decrease in $\theta$ under the hybrid coordination contract.

\section{Proof. See “Appendix H.”}

Theorem 11 shows that with the introduction of a quantity discount mechanism in a trade credit contract that considers the level of sales effort, the retailer is encouraged to increase the order quantity by reducing the wholesale price of products. At the same time, under the hybrid coordination contract, with the decrease in $\theta$ and the decrease in the wholesale price of the manufacturer's products, the retailer is encouraged to improve the optimal effort level and increase its order quantity.

To achieve the perfect coordination of the supply chain system under the hybrid coordination contract, the retailer's order quantity needs to increase to $q_{2}^{s}$.
Theorem 12. When the quantity discount ratio $\theta$ offered by the manufacturer satisfies the following conditions

$$
\bar{\theta}=\frac{\left(1+i_{m} t\right) c_{m}}{p_{m}},
$$

quantity discount contract based on the trade credit can make the supply chain reach the optimal state. In the meantime, $\bar{\theta}$ increases with the increase in the trade credit period $t$.

\section{Proof. See “Appendix I.”}

Theorem 12 shows that the quantity discount ratio $\bar{\theta}$ causing the supply chain to achieve the coordination increases with the increase of the trade credit period provided by the manufacturer. It can be further analyzed that when the trade credit period $t$ increases, the manufacturer's commitment to the capital opportunity cost will increase, so it will improve the discount ratio $\bar{\theta}$ to make up for its own losses. Similarly, when the trade credit period $t$ is reduced, the manufacturer can compensate for the reduction in the retailer's earnings by reducing the quantity discount ratio $\bar{\theta}$.

According to Theorem 12, the manufacturer's expected profit is zero when the supply chain achieves the perfect coordination, which is unacceptable to the manufacturer. To achieve coordination, it is necessary to reallocate the total revenue $\prod_{3}^{s}\left(q_{2}^{s}, e_{2}^{s}\right)$ of the supply chain system, which assigns $\varphi$ proportion of $\prod_{3}^{s}\left(q_{2}^{s}, e_{2}^{s}\right)$ to the manufacturer and $1-\varphi$ ratio to the retailer. After the reallocation, the manufacturer's expected revenue $\prod_{4}^{r}\left(q_{2}^{s}, e_{2}^{s}\right)$ should not be lower than the expected revenue $\prod_{2}^{r}\left(q_{2}^{r}, e_{2}^{r}\right)$ without the introduction of the quantity discount contract, and the retailer's expected revenue $\prod_{4}^{m}\left(q_{2}^{s}, e_{2}^{s}\right)$ should not be lower than the expected revenue $\prod_{2}^{m}\left(q_{2}^{r}, e_{2}^{r}\right)$ without the introduction of quantity discount contract.

Theorem 13. When the income distribution ratio $\varphi$ meets the following condition $\varphi_{1} \leq \varphi \leq \varphi_{2}$,

$$
\begin{aligned}
& \varphi_{1}=\frac{\left(p_{m}-\left(1+i_{m} t\right) c_{m}\right) q_{2}^{r}}{e_{2}^{s}\left(1+i_{r} t\right)\left(p_{r}-v\right) R\left(q_{1}^{s}\right)-C\left(e_{2}^{s}\right)}, \\
& \varphi_{2} \\
& =\frac{\left(1+i_{r} t\right)\left(p_{r}-v\right)\left(e_{2}^{s} R\left(q_{1}^{s}\right)-e_{2}^{r} R\left(q_{1}^{r}\right)\right)+C\left(e_{2}^{r}\right)-C\left(e_{2}^{s}\right)}{e_{2}^{s}\left(1+i_{r} t\right)\left(p_{r}-v\right) R\left(q_{1}^{s}\right)-C\left(e_{2}^{s}\right)} .
\end{aligned}
$$

At this time, the manufacturer is willing to provide the quantity discount ratio which meets (24), and the expressions $\prod_{4}^{r}\left(q_{2}^{s}, e_{2}^{s}\right) \geq \prod_{2}^{r}\left(q_{2}^{r}, e_{2}^{r}\right)$ and $\prod_{4}^{m}\left(q_{2}^{s}, e_{2}^{s}\right) \geq \prod_{2}^{m}\left(q_{2}^{r}, e_{2}^{r}\right)$ have been established.

\section{Proof. See “Appendix J.”}

Theorem 13 shows that in the case of the market demand affected by the retailer's sales effort level, when the quantity discount ratio $\theta$ and the profit distribution ratio $\varphi$ satisfy (24) and (25), the portfolio coordination contract of the trade credit considering the sales effort level and the quantity discount can realize the coordination of the supply chain; that 


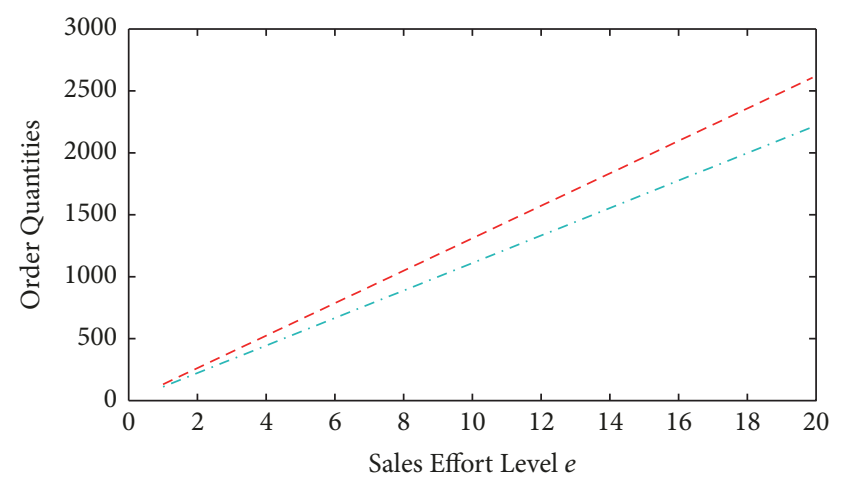

- - Order Quantities for Retailers $q_{2}^{r}$

- - Order Quantities for Supply Chain System $q_{2}^{s}$

FIGURE 1: Chang trend of order quantity of retailer and supply chain with sales effort level $(t=1)$.

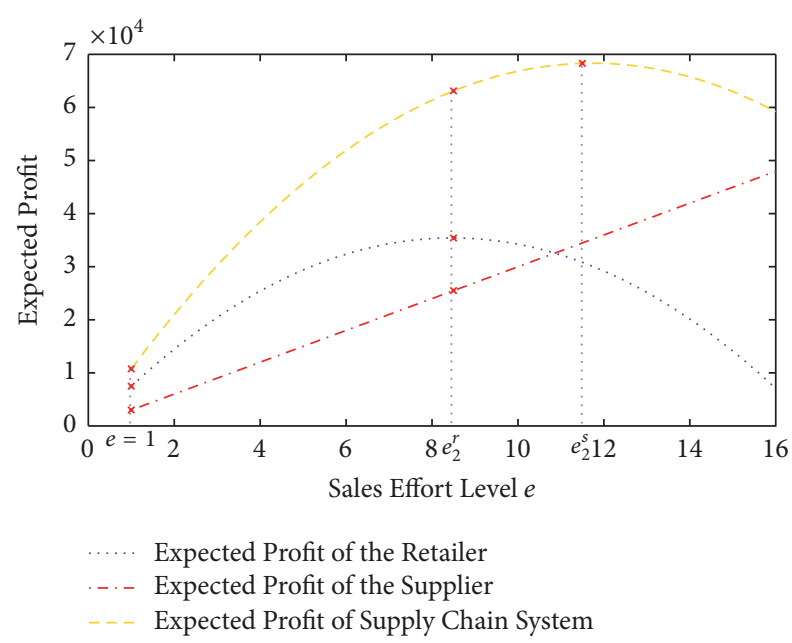

FIGURE 2: Chang trend of expected profit of retailer and manufacturer and supply chain with sales effort level $(t=1)$.

is, the system stays to achieve the optimal state. By adjusting the distribution of the system income through the parameter $\varphi$, the flexibility of the system is increased and the effective cooperation between the two is promoted.

\section{An Illustrating Example}

We now employ numerical examples to further analyze the trade credit model and the hybrid model integrating trade credit and quantity discount when the sales effort influences the market demand. In the supply chain configuration, we suppose that $p_{m}=60, p_{r}=188, c_{r}=40, v=20$, $i_{m}=10 \%, i_{r}=12 \%$; assume the sales effort cost follows $C(e)=500(e-1)^{2}$ and the market demand $\delta$ is subject to normal distribution; that is, $\delta \sim N\left(100,50^{2}\right)$.

First, we analyze the impact of the retailer's sales effort level on the order quantity and the expected profit. The results are shown in Figures 1 and 2.

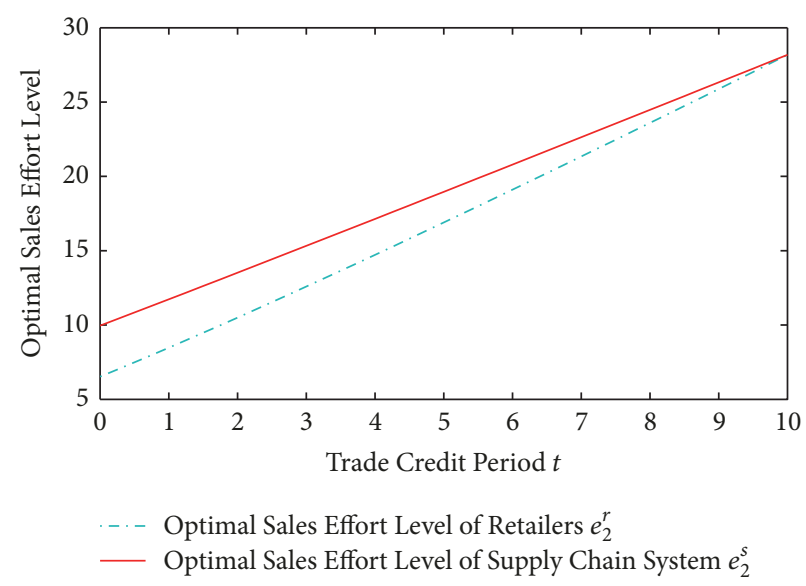

Figure 3: Chang trend of optimal sales effort level of retailer and supply chain with trade credit period.

As seen in Figure 1, in the case that the credit period is determined, the increase in the level of sales effort can prompt the retailer and supply chain system to, respectively, improve the order quantity. This is because the level of sales effort has an impact on the market demand, which indirectly increases the number of products ordered by increasing the market demand, thus increasing the order of the supply chain system.

As found in Figure 2, the expected profit of the retailer tends to rise first and then fall with the increase of the sales effort level. When $e=e_{2}^{r}$, the benefits and the effort costs coming with increasing the order quantity reach equilibrium, so the retailer can receive its maximum expected profit. The manufacturer's expected profit increases with the increase of the sales effort level, so it is beneficial for the manufacturer when the retailer invests more effort. The expected profit of the supply chain system tends to rise first and then fall with the increase of the sales effort level. When $e=e_{2}^{s}$, the system can receive the maximum expected profit. However, in the real world, the retailer does not incur a higher sales effort level than $e_{2}^{r}$, so the retailer and manufacturer's expected profit will increase with the increase of the sales effort level on $e \in\left[1, e_{2}^{r}\right]$. Similarly, the supply chain system does not incur a higher sales effort level than $e_{2}^{s}$, so the expected profit of supply chain system will increase with the increase of sales effort level on $e \in\left[1, e_{2}^{s}\right]$.

Then, the analysis is done about the impact of trade credit period on the decision and the optimal expectation profits of the retailer, the manufacturer, and the supply chain system. First, according to the equation $t<\left(p_{m}-c_{m}\right) / c_{m} i_{m}$ in Section 3.1, the range of credit period $t$ in $0<t<10$ is determined based on the above data set. Figures 3, 4, and 5 are obtained by using MATLAB software for the developed model.

As seen in Figures 3 and 4, the trade credit period provided by the manufacturer has a positive impact on the optimal sales effort level and optimal order quantity for the retailer and the supply chain system. As found in Figure 5, the optimal expected profits of both the retailer and the supply chain system increase with the increase in the trade credit 


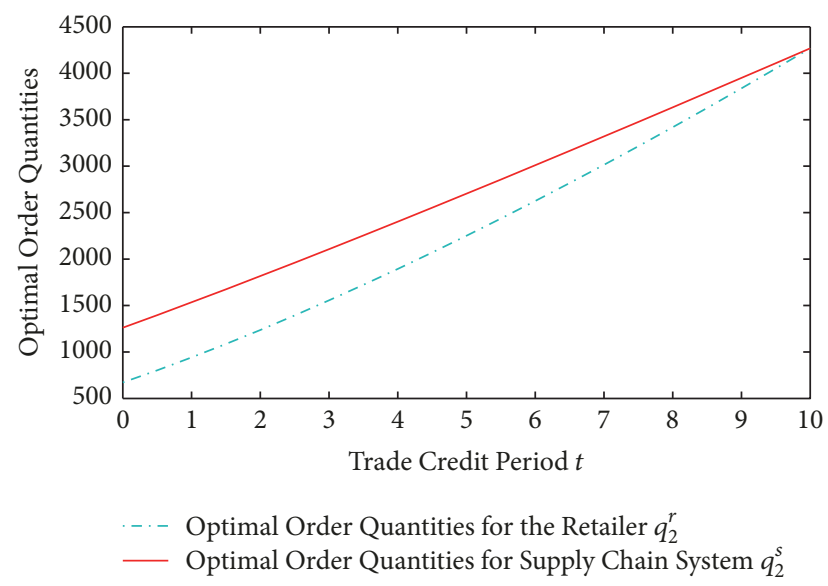

Figure 4: Chang trend of optimal order quantity of retailer and supply chain with trade credit period.

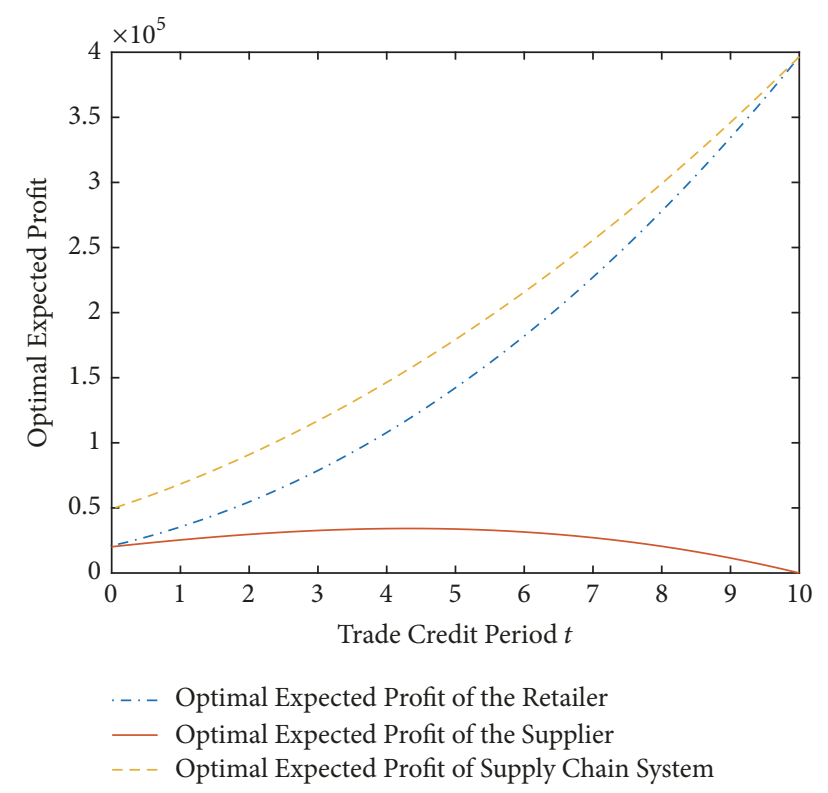

FIGURE 5: Chang trend of optimal expected profits of retailer and manufacturer and supply chain with trade credit period.

period, but the optimal expected profit of the manufacturer decreases with the increase in the trade credit period. This is because if the manufacturer allows the retailer to delay the payment of goods, the retailer could use this payment to invest and gain investment income, and the manufacturer would increase capital opportunity cost.

As is seen from Figure 6, the longer is the trade credit period $t$ provided by the manufacturer, the greater is the quantity discount ratio $\bar{\theta}$, which means that the manufacturer can adjust the $t$ and $\bar{\theta}$ parameters to balance its own decisions. When the trade credit period $t$ increases, the manufacturer takes on greater capital opportunity costs, but it can increase the discount ratio $\bar{\theta}$ to make up for its own loss, and when the trade credit period $t$ decreases, the manufacturer can

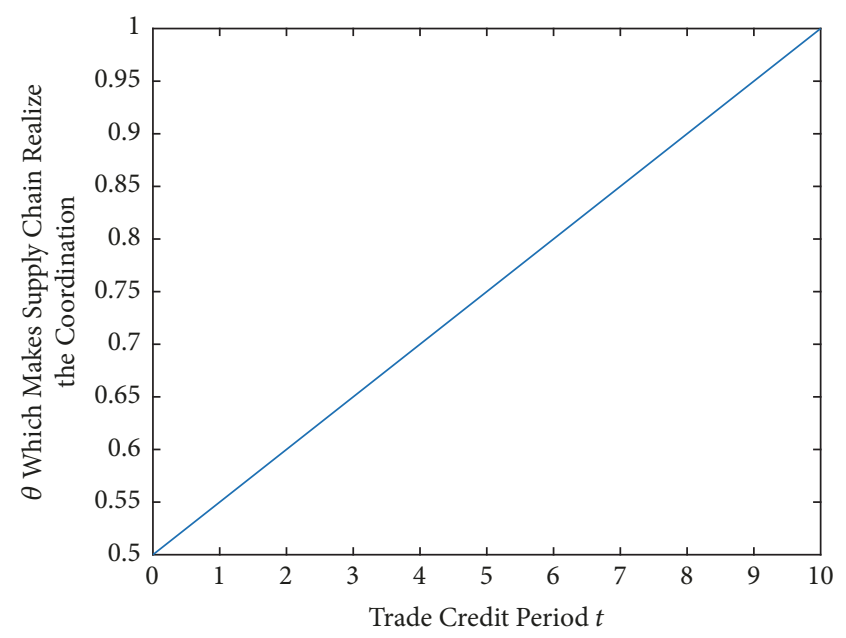

FIGURE 6: Chang trend of quantity discount ratio with trade credit period when the supply chain reaches coordination.

compensate for the reduction in its profit by reducing the quantity discount radio $\bar{\theta}$.

\section{Conclusions}

Considering trade credit as a tool for supply chain coordination, when market demand is influenced by retailer sales effort, we construct the quantitative models in a newsvendor framework, respectively, based on the single trade credit contract and the composite contract combining trade credit and quantity discount. And we calculate and analyze the models by Stackelberg game theory and optimization theory. Some interesting insights are obtained as follows.

First, when retailer sales effort influences market demand, a single trade credit cannot perfectly coordinate the supply chain; that is, the optimal sales effort level and order quantity and system's profit under the decentralized decision scenario are lower than those under the centralized decision scenario.

Second, based on a single trade credit, when retailer sales effort influences market demand, the optimal order quantities as well as the optimal profits of the manufacturer, retailer, and supply chain are higher than those when retailer sales effort does not influence market demand. Whether under decentralized decision scenario or under centralized decision scenario, when sales effort influences the market demand, the optimal effort level and optimal order quantity increase as trade credit period increases, respectively.

Third, considering trade credit and order quantity discount and sales effort effects on the demand, we show that when model parameters meet certain conditions, the composite contract combining trade credit and quantity discount can realize the perfect coordination of supply chain and a "win-win" outcome. Furthermore, the composite contract can provide great flexibility in coordinating the supply chain through adjusting relevant parameters.

In future studies, we can extend the models to the threetier supply chain (manufacturer-retailer-consumer supply 
chain). And we can also continue the study from the perspective of information asymmetry. For example, when the sales effort is private information of the retailer, we explore the supply chain coordination under trade credit.

\section{Appendix}

\section{A. Proof of Proposition 1}

We take the partial derivatives of (5) and obtain

$$
\begin{aligned}
\frac{\partial^{2} \prod_{2}^{r}(q, e)}{\partial q^{2}}= & -\frac{1}{e}\left(1+i_{r} t\right)\left(p_{r}-v\right) f\left(\frac{q}{e}\right) ; \\
\frac{\partial^{2} \prod_{2}^{r}(q, e)}{\partial e^{2}}= & -\frac{q^{2}}{e^{3}}\left(1+i_{r} t\right)\left(p_{r}-v\right) f\left(\frac{q}{e}\right) \\
& -\frac{d^{2} C(e)}{d e^{2}} ; \\
\frac{\partial^{2} \prod_{2}^{r}(q, e)}{\partial q \partial e}= & \frac{q}{e^{2}}\left(1+i_{r} t\right)\left(p_{r}-v\right) f\left(\frac{q}{e}\right) ; \\
\frac{\partial^{2} \prod_{2}^{r}(q, e)}{\partial e \partial q}= & \frac{q}{e^{2}}\left(1+i_{r} t\right)\left(p_{r}-v\right) f\left(\frac{q}{e}\right) ;
\end{aligned}
$$

in addition, with the assumptions $p_{r}>v, d^{2} C(e) / d e^{2}>$ 0 , the Hessian matrix of the binary function $\prod_{2}^{r}(q, e)$ can be determined:

$$
\begin{aligned}
&|H|=\left|\begin{array}{ll}
\frac{\partial^{2} \prod_{2}^{r}(q, e)}{\partial q^{2}} & \frac{\partial^{2} \prod_{2}^{r}(q, e)}{\partial q \partial e} \\
\frac{\partial^{2} \prod_{2}^{r}(q, e)}{\partial e \partial q} & \frac{\partial^{2} \prod_{2}^{r}(q, e)}{\partial e^{2}}
\end{array}\right| \\
&= \frac{\partial^{2} \prod_{2}^{r}(q, e)}{\partial q^{2}} \times \frac{\partial^{2} \prod_{2}^{r}(q, e)}{\partial e^{2}}-\frac{\partial^{2} \prod_{2}^{r}(q, e)}{\partial q \partial e} \\
& \times \frac{\partial^{2} \prod_{2}^{r}(q, e)}{\partial e \partial q} \\
&= \frac{1}{e}\left(1+i_{r} t\right)\left(p_{r}-v\right) f\left(\frac{q}{e}\right) \frac{d^{2} C(e)}{d e^{2}}>0, \\
& \frac{\partial^{2} \prod_{2}^{r}(q, e)}{\partial q^{2}}<0, \frac{\partial^{2} \prod_{2}^{r}(q, e)}{\partial e^{2}}<0 .
\end{aligned}
$$

Therefore, according to optimization theory, $\prod_{2}^{r}(q, e)$ has the only optimal solution $\left(q_{2}^{r}, e_{2}^{r}\right)$ on $q \in(0,+\infty) \cup e \in$ $[1,+\infty)$, and, respectively, satisfies the following first order conditions:

$$
\begin{aligned}
\frac{\partial \prod_{2}^{r}(q, e)}{\partial q}= & \left(1+i_{r} t\right) p_{r}-c_{r}-p_{m} \\
& -\left(1+i_{r} t\right)\left(p_{r}-v\right) F\left(\frac{q}{e}\right)=0,
\end{aligned}
$$

$$
\begin{aligned}
\frac{\partial \prod_{2}^{r}(q, e)}{\partial e}= & -\left(1+i_{r} t\right)\left(p_{r}-v\right) \int_{0}^{q / e} F(\delta) d \delta \\
& +\frac{q}{e}\left(1+i_{r} t\right)\left(p_{r}-v\right) F\left(\frac{q}{e}\right)-\frac{d C(e)}{d e} \\
= & 0 .
\end{aligned}
$$

At this time, the retailer's optimal order quantity $q_{2}^{r}$ can be obtained:

$$
q_{2}^{r}=e F^{-1}\left(1-\frac{c_{r}+p_{m}-\left(1+i_{r} t\right) v}{\left(1+i_{r} t\right)\left(p_{r}-v\right)}\right) .
$$

Additionally, the optimal effort level $e_{2}^{r}$ of the retailer meets the condition

$$
\frac{d C\left(e_{2}^{r}\right)}{d e_{2}^{r}}=\left(1+i_{r} t\right)\left(p_{r}-v\right) R\left(\frac{q}{e_{2}^{r}}\right) .
$$

Here $R(q)=\int_{0}^{q} \delta d F(\delta)$.

Only when (A.4) satisfies (A.5), the retailer is able to achieve the greatest gain. Thus, the optimal order quantity of the retailer is $q_{2}^{r}=e_{2}^{r} q_{1}^{r}$, and the optimal selling effort level $e_{2}^{r}$ satisfies

$$
\frac{d C\left(e_{2}^{r}\right)}{d e_{2}^{r}}=\left(1+i_{r} t\right)\left(p_{r}-v\right) R\left(q_{1}^{r}\right) .
$$

Hence, we conclude the proof.

\section{B. Proof of Proposition 4}

We take the partial derivatives of (13) and obtain

$$
\begin{aligned}
\frac{\partial^{2} \prod_{2}^{s}(q, e)}{\partial q^{2}}= & -\frac{1}{e}\left(1+i_{r} t\right)\left(p_{r}-v\right) f\left(\frac{q}{e}\right) ; \\
\frac{\partial^{2} \prod_{2}^{s}(q, e)}{\partial e^{2}}= & -\frac{q^{2}}{e^{3}}\left(1+i_{r} t\right)\left(p_{r}-v\right) f\left(\frac{q}{e}\right) \\
& -\frac{d^{2} C(e)}{d e^{2}} ; \\
\frac{\partial^{2} \prod_{2}^{s}(q, e)}{\partial q \partial e}= & \frac{q}{e^{2}}\left(1+i_{r} t\right)\left(p_{r}-v\right) f\left(\frac{q}{e}\right) ; \\
\frac{\partial^{2} \prod_{2}^{s}(q, e)}{\partial e \partial q}= & \frac{q}{e^{2}}\left(1+i_{r} t\right)\left(p_{r}-v\right) f\left(\frac{q}{e}\right) ;
\end{aligned}
$$

in addition, with the assumptions $p_{r}>v, d^{2} C(e) / d e^{2}>0$, the Hessian matrix $|H|$ of the binary function $\prod_{2}^{s}(q, e)$ can be determined. Here,

$$
|H|>0,
$$

$$
\begin{gathered}
\frac{\partial^{2} \prod_{2}^{r}(q, e)}{\partial q^{2}}<0, \\
\frac{\partial^{2} \prod_{2}^{r}(q, e)}{\partial e^{2}}<0 .
\end{gathered}
$$


Therefore, according to optimization theory, $\prod_{2}^{s}(q, e)$ has the only optimal solution $\left(q_{2}^{s}, e_{2}^{s}\right)$, and, respectively, satisfies the following first order conditions:

$$
\begin{aligned}
\frac{\partial \prod_{2}^{s}(q, e)}{\partial q}= & \left(1+i_{r} t\right) p_{r}-c_{r}-\left(1+i_{m} t\right) c_{m} \\
& -\left(1+i_{r} t\right)\left(p_{r}-v\right) F\left(\frac{q}{e}\right)=0, \\
\frac{\partial \prod_{2}^{s}(q, e)}{\partial e}= & -\left(1+i_{r} t\right)\left(p_{r}-v\right) \int_{0}^{q / e} F(\delta) d \delta \\
& +\frac{q}{e}\left(1+i_{r} t\right)\left(p_{r}-v\right) F\left(\frac{q}{e}\right) \frac{d C(e)}{d e} \\
= & 0 .
\end{aligned}
$$

Then, it is obtained that

$$
q_{2}^{s}=e F^{-1}\left(1-\frac{c_{r}+\left(1+i_{m} t\right) c_{m}-\left(1+i_{r} t\right) v}{\left(1+i_{r} t\right)\left(p_{r}-v\right)}\right),
$$

$d C\left(e_{2}^{s}\right) / d e_{2}^{s}=\left(1+i_{r} t\right)\left(p_{r}-v\right) R\left(q / e_{2}^{s}\right)$. Here, $R(q)=\int_{0}^{q} \delta d F(\delta)$.

Equation (B.4) shows the relationship between the optimal order quantity and the sales effort level, so the optimal order quantity of the system needs to meet $q_{2}^{s}=e_{2}^{s} q_{1}^{s}=$ $e_{2}^{s} F^{-1}\left(1-\left(c_{r}+\left(1+i_{m} t\right) c_{m}-\left(1+i_{r} t\right) v\right) /\left(1+i_{r} t\right)\left(p_{r}-v\right)\right)$ in order to ensure the system's best benefits, and the optimal sales effort level $e_{2}^{s}$ meets

$$
\frac{d C\left(e_{2}^{s}\right)}{d e_{2}^{s}}=\left(1+i_{r} t\right)\left(p_{r}-v\right) R\left(q_{1}^{s}\right) .
$$

Therefore, the system's optimal expected profit is $\prod_{2}^{s}\left(q_{2}^{s}, e_{2}^{s}\right)=e_{2}^{s}\left(1+i_{r} t\right)\left(p_{r}-v\right) R\left(q_{1}^{s}\right)-C\left(e_{2}^{s}\right)$. Hence, we conclude the proof.

\section{Proof of Theorem 6}

Let $\prod_{2}^{s}(q, e)=e\left(1+i_{r} t\right)\left(p_{r}-v\right) R\left(q_{1}^{s}\right)-C(e)$, where $q=e q_{1}^{s}$. The first order partial derivative of $e$ for equation $\prod_{2}^{s}(q, e)$ is

$$
\frac{\partial \prod_{2}^{s}(q, e)}{\partial e}=\left(1+i_{r} t\right)\left(p_{r}-v\right) R\left(q_{1}^{s}\right)-\frac{d C(e)}{d e},
$$

and it is known that $d C\left(e_{2}^{s}\right) / d e_{2}^{s}=\left(1+i_{r} t\right)\left(p_{r}-v\right) R\left(q_{1}^{s}\right)$ from (15). Then, it is obtained that

$$
\frac{\partial \prod_{2}^{s}(q, e)}{\partial e}=\frac{d C\left(e_{2}^{s}\right)}{d e_{2}^{s}}-\frac{d C(e)}{d e} .
$$

Then, $C^{\prime}(e)$ is monotonically increasing on $e \in\left[1, e_{2}^{s}\right]$ because $d^{2} C(e) / d e^{2}>0$; it can be obtained that $d C(e) / d e \leq$ $d C\left(e_{2}^{s}\right) / d e_{2}^{s}$; that is, $\partial \prod_{2}^{s}(q, e) / \partial e \geq 0$; further it is obtained that $\prod_{2}^{s}(q, e)$ is an increasing function on $e \in\left[1, e_{2}^{s}\right]$. At this time, the level of sales effort in the supply chain system varies from 1 to $e_{2}^{s}$, and the expected return of the entire system is improved.

$\prod_{2}^{s}(q, e)=\prod_{2}^{s}\left(q_{1}^{s}, e=1\right)$ is accurate when the sales effort level remains constant $(e=1)$. Therefore, $\prod_{2}^{s}\left(q=e_{2}^{s} q_{1}^{s}, e_{2}^{s}\right)>$ $\prod_{2}^{s}\left(q=q_{1}^{s}, e=1\right)$ proves to be correct; that is, $\prod_{2}^{s}\left(q_{2}^{s}, e_{2}^{s}\right)>$ $\prod_{2}^{s}\left(q_{1}^{s}, e=1\right)$. Hence, we conclude the proof.

\section{Proof of Theorem 7}

(1) We take the derivative of $t$ for (9) and obtain

$$
\begin{aligned}
\frac{d\left(d C\left(e_{2}^{r}\right) / d e_{2}^{r}\right)}{d e_{2}^{r}} \frac{d e_{2}^{r}}{d t}= & i_{r}\left(p_{r}-v\right) R\left(q_{1}^{r}\right) \\
& +\left(1+i_{r} t\right)\left(p_{r}-v\right) \frac{d R\left(q_{1}^{r}\right)}{d t}
\end{aligned}
$$

where

$$
\begin{gathered}
\frac{d R\left(q_{1}^{r}\right)}{d t}=\frac{i_{r}\left(c_{r}+p_{m}\right)}{\left(1+i_{r} t\right)^{2}\left(p_{r}-v\right)}\left(F^{-1}(1\right. \\
\left.\left.-\frac{c_{r}+p_{m}-\left(1+i_{r} t\right) v}{\left(1+i_{r} t\right)\left(p_{r}-v\right)}\right)\right)^{\prime} q_{1}^{r} f\left(q_{1}^{r}\right) .
\end{gathered}
$$

Because $F(\delta)$ is a continuously differentiable and reversible strictly increasing function,

$$
\left(F^{-1}\left(1-\frac{c_{r}+p_{m}-\left(1+i_{r} t\right) v}{\left(1+i_{r} t\right)\left(p_{r}-v\right)}\right)\right)^{\prime}>0
$$

is right; thus it can be obtained that $d R\left(q_{1}^{r}\right) / d t>0$, and for $R\left(q_{1}^{r}\right)=\int_{0}^{q_{1}^{r}} \delta d F(\delta)=\int_{0}^{q_{1}^{r}} \delta f(\delta) d \delta$, it is known that $\delta f(\delta)>0$ and $q_{1}^{r}>0$, so $R\left(q_{1}^{r}\right)>0$ is right. Then, the right-hand side of (15) is greater than zero.

In addition, according to the assumption that $C(e)$ in the interval $e \in[1,+\infty)$ is a monotonically increasing convex function, the first part of the left-hand side of (15) is greater than 0 , so $d e_{2}^{r} / d t>0$ is established.

We take the derivative of $t$ for (15) and obtain

$$
\begin{aligned}
& \frac{d\left(d C\left(e_{2}^{s}\right) / d e_{2}^{s}\right)}{d e_{2}^{s}} \frac{d e_{2}^{s}}{d t} \\
& \quad=i_{r}\left(p_{r}-v\right) R\left(q_{1}^{s}\right)+\left(1+i_{r} t\right)\left(p_{r}-v\right) \frac{d R\left(q_{1}^{s}\right)}{d t},
\end{aligned}
$$

where

$$
\begin{aligned}
& \frac{d R\left(q_{1}^{s}\right)}{d t}=\frac{i_{r} c_{r}+c_{m}\left(i_{r}-i_{m}\right)}{\left(1+i_{r} t\right)^{2}\left(p_{r}-v\right)} \\
& \quad \times\left(F^{-1}\left(1-\frac{c_{r}+\left(1+i_{m} t\right) c_{m}-\left(1+i_{r} t\right) v}{\left(1+i_{r} t\right)\left(p_{r}-v\right)}\right)\right)^{\prime} \\
& \cdot q_{1}^{s} f\left(q_{1}^{s}\right) .
\end{aligned}
$$

In addition, according to $i_{r}>i_{m}$, it is obtained that $d R\left(q_{1}^{s}\right) / d t>0$. Similarly, $d e_{2}^{s} / d t>0$ is available, so the retailer's optimal effort level $e_{2}^{r}$ and the supply chain system's optimal effort level $e_{2}^{s}$ increase with the increase of the trade credit period $t$. 
(2) We take the derivative of $t$ for (7) and obtain

$$
\begin{aligned}
\frac{d q_{2}^{r}}{d t} & =\frac{d e_{2}^{r}}{d t} F^{-1}\left(1-\frac{c_{r}+p_{m}-\left(1+i_{r} t\right) v}{\left(1+i_{r} t\right)\left(p_{r}-v\right)}\right)+e_{2}^{r} \\
& \cdot \frac{i_{r}\left(c_{r}+p_{m}\right)}{\left(1+i_{r} t\right)^{2}\left(p_{r}-v\right)}\left(F^{-1}(1\right. \\
& \left.\left.-\frac{c_{r}+p_{m}-\left(1+i_{r} t\right) v}{\left(1+i_{r} t\right)\left(p_{r}-v\right)}\right)\right)^{\prime} .
\end{aligned}
$$

Because $d e_{2}^{c} / d t>0$ has proven to be correct, it is known that $d q_{2}^{c} / d t>0$. It is obtained that

$$
q_{2}^{s}=e_{2}^{s} F^{-1}\left(1-\frac{c_{r}+\left(1+i_{m} t\right) c_{m}-\left(1+i_{r} t\right) v}{\left(1+i_{r} t\right)\left(p_{r}-v\right)}\right)
$$

from equation (14).

By taking the derivative of $t$ for (14), we obtain

$$
\begin{aligned}
\frac{d q_{2}^{s}}{d t} & =\frac{d e_{2}^{s}}{d t} F^{-1}\left(1-\frac{c_{r}+\left(1+i_{m} t\right) c_{m}-\left(1+i_{r} t\right) v}{\left(1+i_{r} t\right)\left(p_{r}-v\right)}\right) \\
& +e_{2}^{s} \frac{i_{r} c_{r}+c_{m}\left(i_{r}-i_{m}\right)}{\left(1+i_{r} t\right)^{2}\left(p_{r}-v\right)}\left(F^{-1}(1\right. \\
& \left.\left.-\frac{c_{r}+\left(1+i_{m} t\right) c_{m}-\left(1+i_{r} t\right) v}{\left(1+i_{r} t\right)\left(p_{r}-v\right)}\right)\right)^{\prime} .
\end{aligned}
$$

Similarly, $d q_{2}^{s} / d t>0$ is available, so the retailer's optimal order quantity $q_{2}^{r}$ and the supply chain system's optimal order quantity $q_{2}^{s}$ increase with the increase of the trade credit period $t$. Hence, we conclude the proof.

\section{E. Proof of Theorem 8}

(1) With the known condition $\prod_{2}^{r}\left(q_{2}^{r}, e_{2}^{r}\right)=e_{2}^{r}\left(1+i_{r} t\right)\left(p_{r}-\right.$ v) $R\left(q_{1}^{r}\right)-C\left(e_{2}^{r}\right)$, we take the derivative of $t$ for $\prod_{2}^{r}\left(q_{2}^{r}, e_{2}^{r}\right)$ and obtain

$$
\begin{aligned}
& \frac{d \prod_{2}^{r}\left(q_{2}^{r}, e_{2}^{r}\right)}{d t} \\
& =\left[\left(1+i_{r} t\right)\left(p_{r}-v\right) R\left(q_{1}^{r}\right)-\frac{d C\left(e_{2}^{r}\right)}{d e_{2}^{r}}\right] \frac{d e_{2}^{r}}{d t} \\
& \quad+e_{2}^{r} i_{r}\left(p_{r}-v\right) R\left(q_{1}^{r}\right) \\
& \quad+e_{2}^{r}\left(1+i_{r} t\right)\left(p_{r}-v\right) \frac{d R\left(q_{1}^{r}\right)}{d t} .
\end{aligned}
$$

It is seen that the first part of the right-hand side of (E.1) is equal to zero from (9), and because $d R\left(q_{1}^{r}\right) / d t>0$, we obtain $d \prod_{2}^{r}\left(q_{2}^{r}, e_{2}^{r}\right) / d t>0$. Therefore, there exists always a minimum trade credit period $\hat{t}$, when the retailer's optimal expected return $\prod_{2}^{r}\left(q_{2}^{r}, e_{2}^{r}\right)$ is $N^{r}$. Then, the following has proven correct: $\prod_{2}^{r}\left(q_{2}^{r}, e_{2}^{r}\right)$ is not lower than $N^{r}$ for $t \in[\hat{t},+\infty)$ and increases as the trade credit period $t$ increases.
(2) With the known condition $\prod_{2}^{s}\left(q_{2}^{s}, e_{2}^{s}\right)=e_{2}^{s}\left(1+i_{r} t\right)\left(p_{r}-\right.$ v) $R\left(q_{1}^{s}\right)-C\left(e_{2}^{s}\right)$, we take the derivative of $t$ for $\prod_{2}^{s}\left(q_{2}^{s}, e_{2}^{s}\right)$ and obtain

$$
\begin{aligned}
& \frac{d \prod_{2}^{s}\left(q_{2}^{s}, e_{2}^{s}\right)}{d t} \\
& =\left[\left(1+i_{r} t\right)\left(p_{r}-v\right) R\left(q_{1}^{s}\right)-\frac{d C\left(e_{2}^{s}\right)}{d e_{2}^{s}}\right] \frac{d e_{2}^{s}}{d t} \\
& \quad+e_{2}^{s} i_{r}\left(p_{r}-v\right) R\left(q_{1}^{s}\right) \\
& \quad+e_{2}^{s}\left(1+i_{r} t\right)\left(p_{r}-v\right) \frac{d R\left(q_{1}^{s}\right)}{d t} .
\end{aligned}
$$

It is seen that the first part of the right-hand side of (E.2) is equal to zero from (15), and because $d R\left(q_{1}^{s}\right) / d t>0$ has proven correct, $d \prod_{2}^{s}\left(q_{2}^{s}, e_{2}^{s}\right) / d t>0$ is established. Therefore, there always exists a minimum trade credit period $\tilde{t}$ when the retailer's optimal expected return $\prod_{2}^{s}\left(q_{2}^{s}, e_{2}^{s}\right)$ is $N^{s}$. Then, the following has proven correct: $\prod_{2}^{s}\left(q_{2}^{s}, e_{2}^{s}\right)$ is not lower than $N^{s}$ for $t \in[\tilde{t},+\infty)$ and increases as the trade credit period $t$ increases.

Hence, we conclude the proof.

\section{F. Proof of Theorem 9}

(1) Because $d R(q) / d q=q f(q)>0$ and then $R\left(q_{1}^{r}\right)<R\left(q_{1}^{s}\right)$ according to $q_{1}^{r}<q_{1}^{s}, R(q)$ is monotonically increasing on $q \in(0, \infty)$. It is easy to know that $d C\left(e_{2}^{r}\right) / d e_{2}^{r}<d C\left(e_{2}^{s}\right) / d e_{2}^{s}$ by comparing (9) with (15), and because $C^{\prime \prime}(e)>0$, that is, $C^{\prime}(e)$ is monotonically increasing on $e \in[1, \infty), e_{2}^{r}<e_{2}^{s}$ is proven to be correct.

(2) $q_{2}^{r}<q_{2}^{s}$ is correct because $q_{1}^{r}<q_{1}^{s}, e_{2}^{r}<e_{2}^{s}$ with known conditions $q_{2}^{r}=e_{2}^{r} q_{1}^{r}, q_{2}^{s}=e_{2}^{s} q_{1}^{s}$.

(3) From (13), we have

$$
\begin{aligned}
\frac{\partial \prod_{2}^{s}(q, e)}{\partial q}= & \left(1+i_{r} t\right) p_{r}-c_{r}-\left(1+i_{m} t\right) c_{m} \\
& -\left(1+i_{r} t\right)\left(p_{r}-v\right) F\left(\frac{q}{e}\right) .
\end{aligned}
$$

Based on $\partial \prod_{2}^{s}(q, e) / \partial q=0$, we obtain

$$
\begin{gathered}
\left(1+i_{r} t\right) p_{r}-c_{r}-\left(1+i_{m} t\right) c_{m} \\
=\left(1+i_{r} t\right)\left(p_{r}-v\right) F\left(\frac{q_{2}^{s}}{e}\right) .
\end{gathered}
$$

Therefore,

$$
\frac{\partial \prod_{2}^{s}(q, e)}{\partial q}=\left(1+i_{r} t\right)\left(p_{r}-v\right)\left(F\left(\frac{q_{2}^{s}}{e}\right)-F\left(\frac{q}{e}\right)\right) .
$$

$F(\delta)$ is strictly increasing function, and $q_{2}^{s}>q_{2}^{r}$, so $\partial \prod_{2}^{s}(q, e) / \partial q>0$ proves correct; that is, $\prod_{2}^{s}(q, e)$ is monotonically increasing on $q \in\left[q_{2}^{r}, q_{2}^{s}\right]$. Therefore, it can be obtained that $\prod_{2}^{s}\left(q_{2}^{r}, e_{2}^{s}\right)<\prod_{2}^{s}\left(q_{2}^{s}, e_{2}^{s}\right)$ from $q_{2}^{r}<q_{2}^{s}$ for any $e$.

Similarly, it is known that

$$
\frac{\partial \prod_{2}^{s}(q, e)}{\partial e}=\left(1+i_{r} t\right)\left(p_{r}-v\right) R\left(\frac{q}{e}\right)-\frac{d C(e)}{d e} .
$$


As $d C\left(e_{2}^{s}\right) / d e_{2}^{s}=\left(1+i_{r} t\right)\left(p_{r}-v\right) R\left(q / e_{2}^{s}\right)$, we obtain $\partial \prod_{2}^{s}(q, e) / \partial e=\left(R(q / e) / R\left(q / e_{2}^{s}\right)\right)\left(d C\left(e_{2}^{s}\right) / d e_{2}^{s}\right)-d C(e) / d e$. $q / e \geq q / e_{2}^{s}$ is established when $e \in\left[e_{2}^{r}, e_{2}^{s}\right]$, so $R(q / e) /$ $R\left(q / e_{2}^{s}\right) \geq 1$. In addition, $d C\left(e_{2}^{s}\right) / d e_{2}^{s} \geq d C(e) / d e$ is also correct, so it can be obtained that $\partial \prod_{2}^{s}(q, e) / \partial e \geq 0$ on $e \in\left[e_{2}^{r}, e_{2}^{s}\right]$; that is, $\prod_{2}^{s}(q, e)$ is monotonically increasing on $e \in\left[e_{2}^{r}, e_{2}^{s}\right]$. Therefore, we can obtain $\prod_{2}^{s}\left(q_{2}^{r}, e_{2}^{r}\right)<\prod_{2}^{s}\left(q_{2}^{r}, e_{2}^{s}\right)$ from $e_{2}^{r}<e_{2}^{s}$ for any $q$ given. Thus, $\prod_{2}^{s}\left(q_{2}^{r}, e_{2}^{r}\right)<\prod_{2}^{s}\left(q_{2}^{s}, e_{2}^{s}\right)$ proves correct.

Hence, we conclude the proof.

\section{G. Proof of Proposition 10}

We take the second order partial conduct of $q$ for (18) and obtain

$$
\frac{\partial^{2} \prod_{3}^{r}(q, e)}{\partial q^{2}}=-\frac{1}{e}\left(1+i_{r} t\right)\left(p_{r}-v\right) f\left(\frac{q}{e}\right) .
$$

It is obvious that $\partial^{2} \prod_{3}^{r}(q, e) / \partial q^{2}<0$ because $f(q / e)>0$ and $p_{r}>v$, so $\prod_{3}^{r}(q, e)$ has the only optimal solution $q_{3}^{r}$ on $q \in(0, \infty)$, which meets

$$
q_{3}^{r}=e F^{-1}\left(1-\frac{c_{r}+\theta p_{m}-\left(1+i_{r} t\right) v}{\left(1+i_{r} t\right)\left(p_{r}-v\right)}\right) .
$$

The retailer's optimal order quantity is $q_{0}$ and meets $q_{0}=$ $F^{-1}\left(1-\left(c_{r}+\theta p_{m}-\left(1+i_{r} t\right) v\right) /\left(1+i_{r} t\right)\left(p_{r}-v\right)\right)$ when $e=1$. obtain

We take the second order partial conduct of $e$ for (18) and

$$
\begin{aligned}
\frac{\partial^{2} \prod_{3}^{r}(q, e)}{\partial e^{2}}= & -\frac{q^{2}}{e^{3}}\left(1+i_{r} t\right)\left(p_{r}-v\right) f\left(\frac{q}{e}\right) \\
& -\frac{d^{2} C(e)}{d e^{2}} .
\end{aligned}
$$

It is obvious that $\partial^{2} \prod_{3}^{r}(q, e) / \partial e^{2}<0$ because $f(q / e)>0$ and $d^{2} C(e) / d e^{2}>0$, so $\prod_{3}^{r}(q, e)$ has the only optimal solution $e_{3}^{r}$ on $e \in[1, \infty)$, which meets

$$
\frac{d C\left(e_{3}^{r}\right)}{d e_{3}^{r}}=\left(1+i_{r} t\right)\left(p_{r}-v\right) R\left(\frac{q}{e_{3}^{r}}\right) .
$$

As a result, the retailer's optimal order quantity is $q_{3}^{r}=$ $e_{3}^{r} q_{0}$, and the optimal sales effort level $e_{3}^{r}$ satisfies

$$
\frac{d C\left(e_{3}^{r}\right)}{d e_{3}^{r}}=\left(1+i_{r} t\right)\left(p_{r}-v\right) R\left(q_{0}\right) .
$$

Hence, we conclude the proof.

\section{H. Proof of Theorem 11}

Comparing (9) and (21), since $0<\theta<1$ and $F^{-1}(\delta)$ is a continuous and monotonically increasing function, it is known that $q_{0}>q_{1}^{r}$, and $R(q)$ is also a monotonically increasing function, so $d C\left(e_{3}^{r}\right) / d e_{3}^{r}>d C\left(e_{2}^{r}\right) / d e_{2}^{r}$. Then, because $C^{\prime}(e)$ is a monotonically increasing function, $e_{3}^{r}>e_{2}^{r}$ has proven correct.
It is obvious that $q_{3}^{r}>q_{2}^{r}$ because $q_{3}^{r}=e_{3}^{r} q_{0}$ and $q_{2}^{r}=e_{2}^{r} q_{1}^{r}$ as well as the fact that $q_{0}>q_{1}^{r}$ and $e_{3}^{r}>e_{2}^{r}$.

We take the first order partial conduct of $\theta$ for (21) and obtain

$$
C^{\prime \prime}\left(e_{3}^{r}\right) \frac{\partial e_{3}^{r}}{\partial \theta}=\left(1+i_{r} t\right)\left(p_{r}-v\right) \frac{\partial R\left(q_{0}\right)}{\partial \theta} .
$$

We obtain $\partial R\left(q_{0}\right) / \partial \theta<0$ from $\partial R\left(q_{0}\right) / \partial \theta=q_{0} f\left(q_{0}\right)\left(\partial q_{0} /\right.$ $\partial \theta)$, where

$$
\begin{gathered}
\frac{\partial q_{0}}{\partial \theta}=\frac{-p_{m}}{\left(1+i_{r} t\right)\left(p_{r}-v\right)}\left(F^{-1}(1\right. \\
\left.\left.-\frac{c_{r}+\theta p_{m}-\left(1+i_{r} t\right) v}{\left(1+i_{r} t\right)\left(p_{r}-v\right)}\right)\right)^{\prime}<0 .
\end{gathered}
$$

And $\partial e_{3}^{r} / \partial \theta<0$ because $C^{\prime \prime}(e)>0$. The following is obtained $\partial q_{3}^{r} / \partial \theta=\left(\partial e_{3}^{r} / \partial \theta\right) q_{0}+e_{3}^{r}\left(\partial q_{0} / \partial \theta\right)$ from the known equation $q_{3}^{r}=e_{3}^{r} q_{0}$. Thus, $\partial q_{3}^{r} / \partial \theta<0$ is obtained from the above conditions $\partial e_{3}^{r} / \partial \theta<0, \partial q_{0} / \partial \theta<0$, so the optimal effort level $e_{3}^{r}$ and the optimal order quantity $q_{3}^{r}$ of the retailer increase with the decrease in $\theta$, respectively.

Hence, we conclude the proof.

\section{Proof of Theorem 12}

(1) If the supply chain is to be coordinated, it must be satisfied that the variables $\left(q_{3}^{r}, e_{3}^{r}\right)$ in the decentralized decision mode equal the variables $\left(q_{2}^{s}, e_{2}^{s}\right)$ in the centralized decision mode. Since

$$
\begin{aligned}
q_{3}^{r} & =e_{3}^{r} q_{0}, \\
q_{2}^{s} & =e_{2}^{s} q_{1}^{s}, \\
\frac{d C\left(e_{3}^{r}\right)}{d e_{3}^{r}} & =\left(1+i_{r} t\right)\left(p_{r}-v\right) R\left(q_{0}\right), \\
\frac{d C\left(e_{2}^{s}\right)}{d e_{2}^{s}} & =\left(1+i_{r} t\right)\left(p_{r}-v\right) R\left(q_{1}^{s}\right),
\end{aligned}
$$

it can be obtained that

$$
\begin{aligned}
\frac{d C\left(e_{3}^{r}\right)}{d e_{3}^{r}} & =\frac{d C\left(e_{2}^{s}\right)}{d e_{2}^{s}}, \\
e_{3}^{r} q_{0} & =e_{2}^{s} q_{1}^{s} .
\end{aligned}
$$

Here,

$$
\begin{aligned}
& q_{0}=F^{-1}\left(1-\frac{c_{r}+\theta p_{m}-\left(1+i_{r} t\right) v}{\left(1+i_{r} t\right)\left(p_{r}-v\right)}\right) \\
& q_{1}^{s}=F^{-1}\left(1-\frac{c_{r}+\left(1+i_{m} t\right) c_{m}-\left(1+i_{r} t\right) v}{\left(1+i_{r} t\right)\left(p_{r}-v\right)}\right) .
\end{aligned}
$$

It is obtained that $\bar{\theta}=\left(1+i_{m} t\right) c_{m} / p_{m}$ by solving (I.2). At that time, the retailer is encouraged to increase his 
order quantity to $q_{2}^{s}$ and realizes the supply chain's perfect coordination. The retailer's expected profit is

$$
\begin{aligned}
\prod_{3}^{r}\left(q_{3}^{r}, e_{3}^{r}\right) & =\prod_{3}^{r}\left(q_{2}^{s}, e_{2}^{s}\right) \\
& =e_{2}^{s}\left(1+i_{r} t\right)\left(p_{r}-v\right) R\left(q_{1}^{s}\right)-C\left(e_{2}^{s}\right) \\
& =\prod_{2}^{s}\left(q_{2}^{s}, e_{2}^{s}\right)=\prod_{3}^{s}\left(q_{2}^{s}, e_{2}^{s}\right) .
\end{aligned}
$$

And the manufacturer's expected profit is

$$
\prod_{3}^{m}\left(q_{3}^{r}, e_{3}^{r}\right)=\prod_{3}^{m}\left(q_{2}^{s}, e_{2}^{s}\right)=0 .
$$

This shows that when the supply chain realizes the coordination, the supply chain system achieves the best income and the retailer enjoys all the benefits, while the manufacturer's earning is 0 .

(2) It can be obtained that $d \bar{\theta} / d t=i_{m} c_{m} / p_{m}>0$ by taking the derivative of $t$ for (24).

Hence, we conclude the proof.

\section{J. Proof of Theorem 13}

In order for the manufacturer to be willing to provide a quantity discount to satisfy (25), the following conditions must be met:

$$
\begin{aligned}
& \prod_{4}^{r}\left(q_{2}^{s}, e_{2}^{s}\right) \geq \prod_{2}^{r}\left(q_{2}^{r}, e_{2}^{r}\right), \\
& \prod_{4}^{m}\left(q_{2}^{s}, e_{2}^{s}\right) \geq \prod_{2}^{m}\left(q_{2}^{r}, e_{2}^{r}\right),
\end{aligned}
$$

where

$$
\begin{aligned}
& \prod_{4}^{r}\left(q_{2}^{s}, e_{2}^{s}\right)=(1-\varphi) \prod_{3}^{s}\left(q_{2}^{s}, e_{2}^{s}\right), \\
& \prod_{4}^{m}\left(q_{2}^{s}, e_{2}^{s}\right)=\varphi \prod_{3}^{s}\left(q_{2}^{s}, e_{2}^{s}\right) .
\end{aligned}
$$

Therefore, by plugging $q_{2}^{s}, e_{2}^{s}, q_{2}^{r}, e_{2}^{r}$ into (J.1) and calculating it, the following are obtained:

$$
\begin{aligned}
& \varphi \geq \frac{\left(p_{m}-\left(1+i_{m} t\right) c_{m}\right) q_{2}^{r}}{e_{2}^{s}\left(1+i_{r} t\right)\left(p_{r}-v\right) R\left(q_{1}^{s}\right)-C\left(e_{2}^{s}\right)}, \\
& \varphi \\
& \leq \frac{\left(1+i_{r} t\right)\left(p_{r}-v\right)\left(e_{2}^{s} R\left(q_{1}^{s}\right)-e_{2}^{r} R\left(q_{1}^{r}\right)\right)+C\left(e_{2}^{r}\right)-C\left(e_{2}^{s}\right)}{e_{2}^{s}\left(1+i_{r} t\right)\left(p_{r}-v\right) R\left(q_{1}^{s}\right)-C\left(e_{2}^{s}\right)}
\end{aligned}
$$

Here,

$$
\varphi_{1}=\frac{\left(p_{m}-\left(1+i_{m} t\right) c_{m}\right) q_{2}^{r}}{e_{2}^{s}\left(1+i_{r} t\right)\left(p_{r}-v\right) R\left(q_{1}^{s}\right)-C\left(e_{2}^{s}\right)},
$$

$\varphi_{2}$

$$
=\frac{\left(1+i_{r} t\right)\left(p_{r}-v\right)\left(e_{2}^{s} R\left(q_{1}^{s}\right)-e_{2}^{r} R\left(q_{1}^{r}\right)\right)+C\left(e_{2}^{r}\right)-C\left(e_{2}^{s}\right)}{e_{2}^{s}\left(1+i_{r} t\right)\left(p_{r}-v\right) R\left(q_{1}^{s}\right)-C\left(e_{2}^{s}\right)} .
$$

Then we obtain the following equation:

$$
\begin{aligned}
\varphi_{2} & -\varphi_{1}=\frac{e_{2}^{s}\left(1+i_{r} t\right)\left(p_{r}-v\right) R\left(q_{1}^{s}\right)-C\left(e_{2}^{s}\right)}{e_{2}^{s}\left(1+i_{r} t\right)\left(p_{r}-v\right) R\left(q_{1}^{s}\right)-C\left(e_{2}^{s}\right)} \\
- & \frac{e_{2}^{r}\left(1+i_{r} t\right)\left(p_{r}-v\right) R\left(q_{1}^{r}\right)-C\left(e_{2}^{r}\right)+\left(p_{m}-\left(1+i_{m} t\right) c_{m}\right) q_{2}^{r}}{e_{2}^{s}\left(1+i_{r} t\right)\left(p_{r}-v\right) R\left(q_{1}^{s}\right)-C\left(e_{2}^{s}\right)} \\
= & \frac{\prod_{2}^{s}\left(q_{2}^{s}, e_{2}^{s}\right)-\prod_{2}^{s}\left(q_{2}^{r}, e_{2}^{r}\right)}{\prod_{2}^{s}\left(q_{2}^{s}, e_{2}^{s}\right)} .
\end{aligned}
$$

It is obvious that $\varphi_{2}-\varphi_{1}>0$ because $\prod_{2}^{s}\left(q_{2}^{s}, e_{2}^{s}\right)>$ $\prod_{2}^{s}\left(q_{2}^{r}, e_{2}^{r}\right)$. Then, the condition $\varphi_{1} \leq \varphi \leq \varphi_{2}$ is established.

Hence, we conclude the proof.

\section{Conflicts of Interest}

The authors declare that there are no conflicts of interest regarding the publication of this paper.

\section{Acknowledgments}

This research is supported by the Plan Project of Shanghai Philosophy and Social Science (2017BGL014) and Innovation Program of Shanghai Municipal Education Commission (2017-01-07-00-03-E00044). It is also supported by the Planning Fund of Humanities and Social Sciences of Ministry of Education of China (17YJA630099) and the National Natural Science Foundation of China (71774029, 71771048, and 71572033).

\section{References}

[1] T.-T. Lin and J.-H. Chou, "Trade credit and bank loan: evidence from chinese firms," International Review of Economics \& Finance, vol. 36, pp. 17-29, 2015.

[2] Y. W. Zhou, Z. L. Wen, and X. L. Wu, "A single-period inventory and payment model with partial trade credit," Computers \& Industrial Engineering, vol. 90, no. 12, pp. 132-145, 2015.

[3] B. Coulibaly, H. Sapriza, and A. Zlate, "Financial frictions, trade credit, and the 2008-09 global financial crisis," International Review of Economics \& Finance, vol. 26, pp. 25-38, 2013.

[4] J. Heydari, M. Rastegar, and C. H. Glock, "A two-level delay in payments contract for supply chain coordination: The case of credit-dependent demand," International Journal of Production Economics, vol. 191, pp. 26-36, 2017.

[5] Y.-C. Tsao, "Channel coordination under two-level trade credits and demand uncertainty," Applied Mathematical Modelling: Simulation and Computation for Engineering and Environmental Systems, vol. 52, pp. 160-173, 2017.

[6] B. Sarkar, W. Ahmed, and N. Kim, "Joint effects of variable carbon emission cost and multi-delay-in-payments under singlesetup-multiple-delivery policy in a global sustainable supply chain," Journal of Cleaner Production, vol. 185, pp. 421-445, 2018.

[7] J. Luo, "Buyer-vendor inventory coordination with credit period incentives," International Journal of Production Economics, vol. 108, no. 1-2, pp. 143-152, 2007.

[8] C. H. Lee and B.-D. Rhee, "Trade credit for supply chain coordination," European Journal of Operational Research, vol. 214, no. 1, pp. 136-146, 2011. 
[9] T. M. Simatupang, I. V. Sandroto, and S. B. H. Lubis, "Supply chain coordination in a fashion firm," Supply Chain Management Review, vol. 9, no. 3, pp. 256-268, 2004.

[10] Q. Pang, Y. Chen, and Y. Hu, "Coordinating three-level supply chain by revenue-sharing contract with sales effort dependent demand," Discrete Dynamics in Nature and Society, vol. 2014, Article ID 561081, 10 pages, 2014.

[11] T. A. Taylor, "Supply chain coordination under channel rebates with sales effort effects," Management Science, vol. 48, no. 8, pp. 992-1007, 2002.

[12] H. Krishnan, R. Kapuscinski, and D. A. Butz, "Coordinating contracts for decentralized supply chains with retailer promotional effort," Management Science, vol. 50, no. 1, pp. 48-63, 2004.

[13] Y.-S. Liu, Y. Shang, and H.-y. Su, "A composite contract for coordinating a supply chain with price and effort dependent stochastic demand," Mathematical Problems in Engineering, vol. 2016, Article ID 3650605, 9 pages, 2016.

[14] S. Xiao, S. P. Sethi, M. Liu, and S. Ma, "Coordinating contracts for a financially constrained supply chain," OMEGA-The International Journal of Management Science, vol. 72, pp. 71-86, 2017.

[15] C. W. Haley and R. C. Higgins, "Inventory policy and trade credit financing," Management Science, vol. 20, no. 4, pp. 464471, 1973.

[16] S. K. Goyal, "Economic order quantity under conditions of permissible delay in payments," Journal of the Operational Research Society, vol. 36, no. 4, pp. 1069-1069, 1985.

[17] Y.-F. Huang, "Optimal retailer's ordering policies in the EOQ model under trade credit financing," Journal of the Operational Research Society, vol. 54, no. 9, pp. 1011-1015, 2003.

[18] J.-T. Teng, H.-L. Yang, and M.-S. Chern, “An inventory model for increasing demand under two levels of trade credit linked to order quantity," Applied Mathematical Modelling: Simulation and Computation for Engineering and Environmental Systems, vol. 37, no. 14-15, pp. 7624-7632, 2013.

[19] A. A. Taleizadeh, M. Lashgari, R. Akram, and J. Heydari, "Imperfect economic production quantity model with upstream trade credit periods linked to raw material order quantity and downstream trade credit periods," Applied Mathematical Modelling: Simulation and Computation for Engineering and Environmental Systems, vol. 40, no. 19-20, pp. 8777-8793, 2016.

[20] G. C. Mahata, "An EPQ-based inventory model for exponentially deteriorating items under retailer partial trade credit policy in supply chain," Expert Systems with Applications, vol. 39, no. 3, pp. 3537-3550, 2012.

[21] H. N. Soni and M. Joshi, "A fuzzy framework for coordinating pricing and inventory policies for deteriorating items under retailer partial trade credit financing," Computers \& Industrial Engineering, vol. 66, no. 4, pp. 865-878, 2013.

[22] S.-C. Chen, J.-T. Teng, and K. Skouri, "Economic production quantity models for deteriorating items with up-stream full trade credit and down-stream partial trade credit," International Journal of Production Economics, vol. 155, pp. 302-309, 2014.

[23] J. Wu, F. B. Al-Khateeb, J.-T. Teng, and L. E. Cárdenas-Barrón, "Inventory models for deteriorating items with maximum lifetime under downstream partial trade credits to creditrisk customers by discounted cash-flow analysis," International Journal of Production Economics, vol. 171, pp. 105-115, 2016.
[24] J. Kim, H. Hwang, and S. W. Shinn, "An optimal credit policy to increase suppliers profit with price-dependent demand functions," Production Planning \& Control, vol. 6, no. 1, pp. 45-50, 1995.

[25] P. L. Abad and C. K. Jaggi, "A joint approach for setting unit price and the length of the credit period for a seller when end demand is price sensitive," International Journal of Production Economics, vol. 83, no. 2, pp. 115-122, 2003.

[26] Y.-W. Zhou, Y. Zhong, and J. Li, "An uncooperative order model for items with trade credit, inventory-dependent demand and limited displayed-shelf space," European Journal of Operational Research, vol. 223, no. 1, pp. 76-85, 2012.

[27] W.-C. Wang, J.-T. Teng, and K.-R. Lou, "Seller's optimal credit period and cycle time in a supply chain for deteriorating items with maximum lifetime," European Journal of Operational Research, vol. 232, no. 2, pp. 315-321, 2014.

[28] Y.-C. Tsao, "A piecewise nonlinear optimization for a production-inventory model under maintenance, variable setup costs, and trade credits," Annals of Operations Research, vol. 233, pp. 465-481, 2015.

[29] P. Pramanik, M. K. Maiti, and M. Maiti, "Three level partial trade credit with promotional cost sharing," Applied Soft Computing, vol. 58, pp. 553-575, 2017.

[30] M. Y. Jaber and I. H. Osman, "Coordinating a two-level supply chain with delay in payments and profit sharing," Computers \& Industrial Engineering, vol. 50, no. 4, pp. 385-400, 2006.

[31] S. Yang, K.-S. Hong, and C. Lee, "Supply chain coordination with stock-dependent demand rate and credit incentives," International Journal of Production Economics, vol. 157, no. 1, pp. 105-111, 2014.

[32] J. Luo and Q. Zhang, "Trade credit: a new mechanism to coordinate supply chain," Operations Research Letters, vol. 40, no. 5, pp. 378-384, 2012.

[33] S. P. Sarmah, D. Acharya, and S. K. Goyal, "Coordination of a single-manufacturer/multi-buyer supply chain with credit option," International Journal of Production Economics, vol. 111, no. 2, pp. 676-685, 2008.

[34] S. K. Chaharsooghi and J. Heydari, "Supply chain coordination for the joint determination of order quantity and reorder point using credit option," European Journal of Operational Research, vol. 204, no. 1, pp. 86-95, 2010.

[35] A. Arkan and S. R. Hejazi, "Coordinating orders in a two echelon supply chain with controllable lead time and ordering cost using the credit period," Computers \& Industrial Engineering, vol. 62, no. 1, pp. 56-69, 2012.

[36] Y.-G. Zhong and Y.-W. Zhou, “Improving the supply chain's performance through trade credit under inventory-dependent demand and limited storage capacity," International Journal of Production Economics, vol. 143, no. 2, pp. 364-370, 2013.

[37] B. C. Das, B. Das, and S. K. Mondal, "Integrated supply chain model for a deteriorating item with procurement cost dependent credit period," Computers \& Industrial Engineering, vol. 64, no. 3, pp. 788-796, 2013.

[38] L. Y. Ouyang, C. H. Ho, C. H. Su et al., "An integrated inventory model with capacity constraint and order-size dependent trade credit," Computers \& Industrial Engineering, vol. 84, no. 6, pp. 133-143, 2015.

[39] Q. Zhang, M. Dong, J. Luo, and A. Segerstedt, "Supply chain coordination with trade credit and quantity discount incorporating default risk," International Journal of Production Economics, vol. 153, pp. 352-360, 2014. 
[40] H. Yang, W. Zhuo, Y. Zha, and H. Wan, "Two-period supply chain with flexible trade credit contract," Expert Systems with Applications, vol. 66, pp. 95-105, 2016.

[41] Y.-C. Tsao, P.-L. Lee, C.-H. Chen, and Z.-W. Liao, "Sustainable newsvendor models under trade credit," Journal of Cleaner Production, vol. 141, pp. 1478-1491, 2017.

[42] E. B. Cao and M. Yu, "Trade credit financing and coordination for an emission-dependent supply chain," Computer \& Industrial Engineering, vol. 119, pp. 50-62, 2018. 


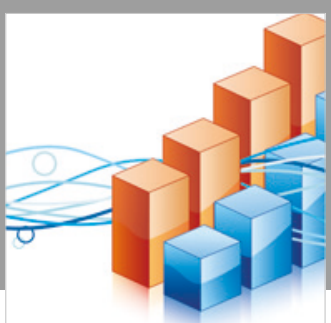

Advances in

Operations Research

\section{-n-m}
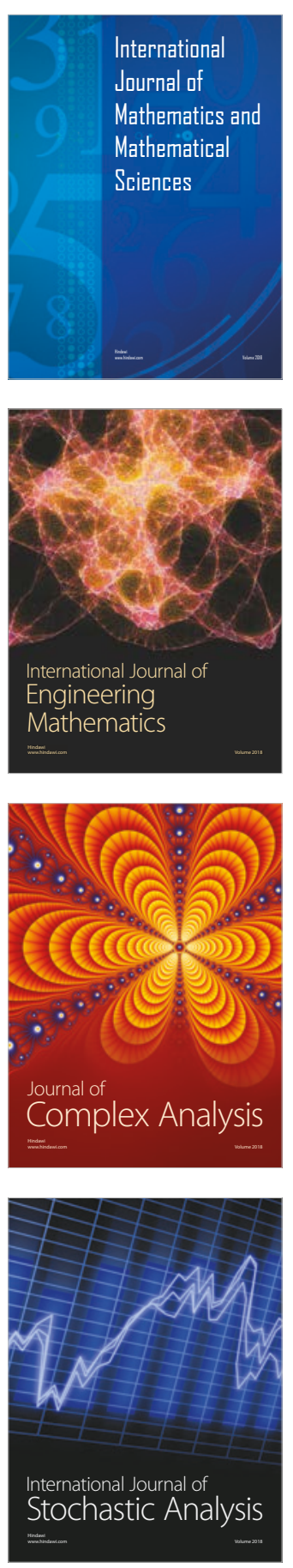
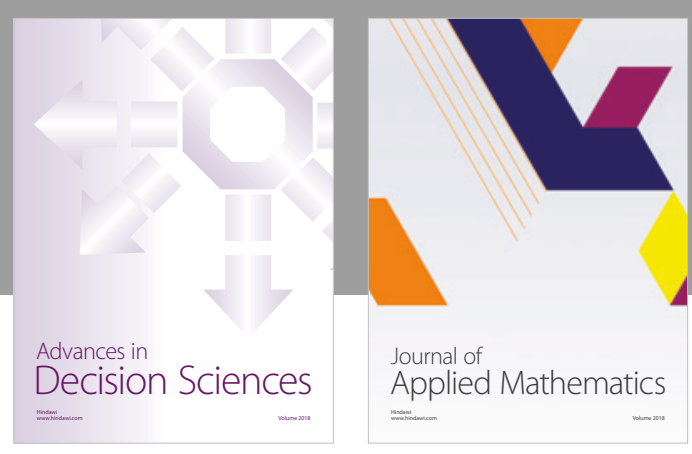

Journal of

Applied Mathematics
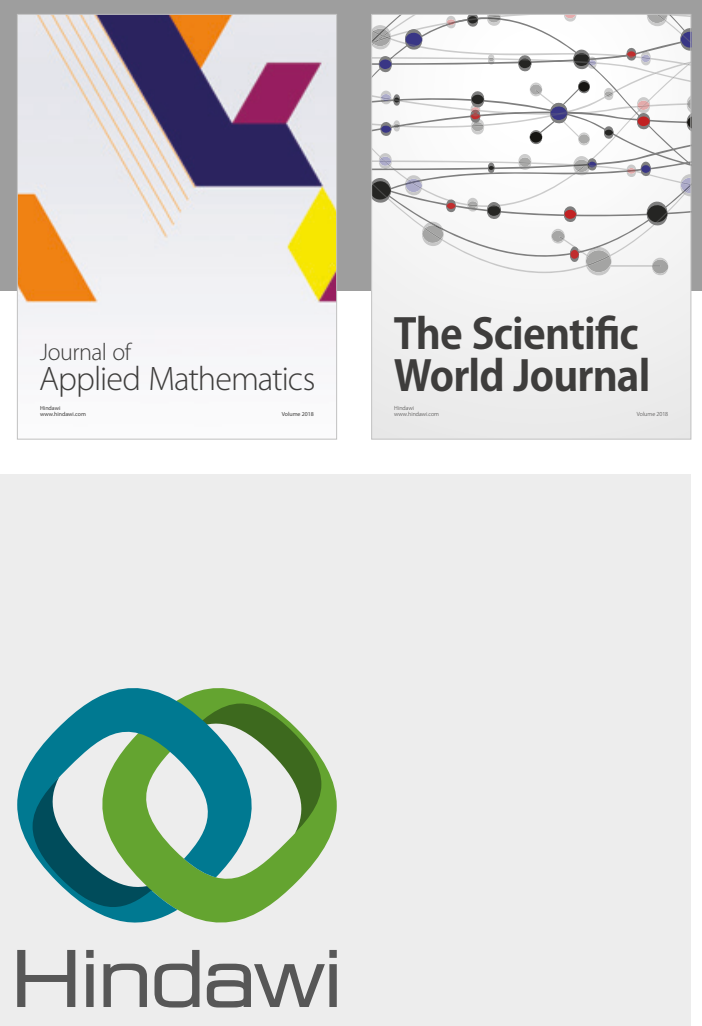

Submit your manuscripts at

www.hindawi.com

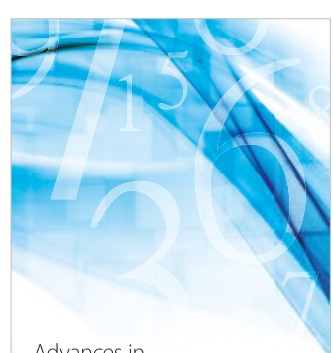

Advances in
Numerical Analysis
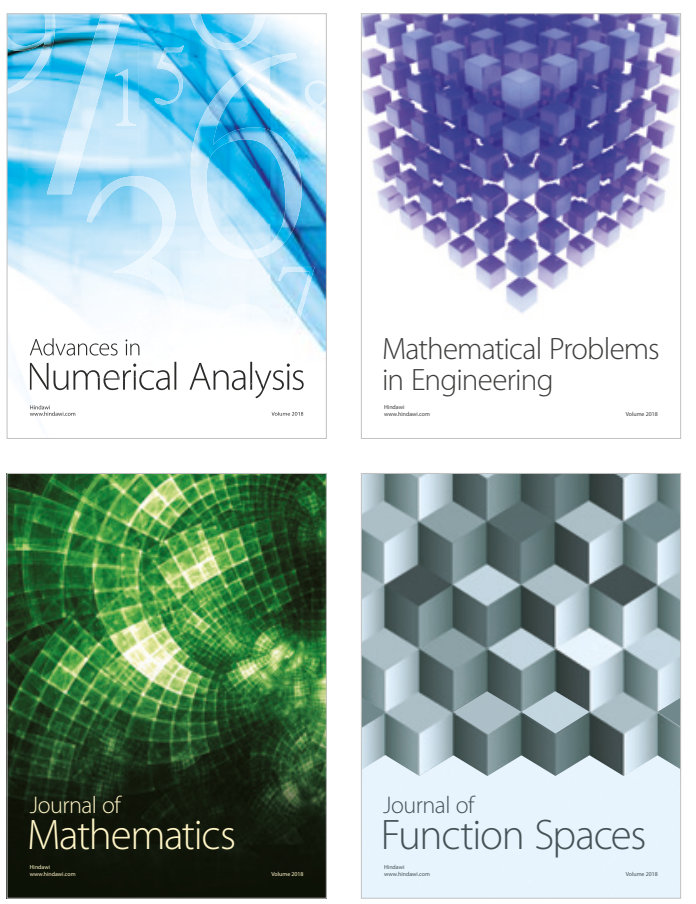

Mathematical Problems in Engineering

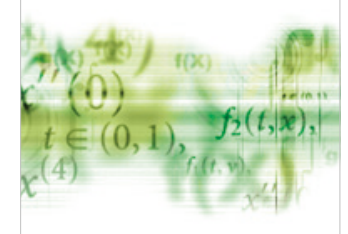

International Journal of

Differential Equations

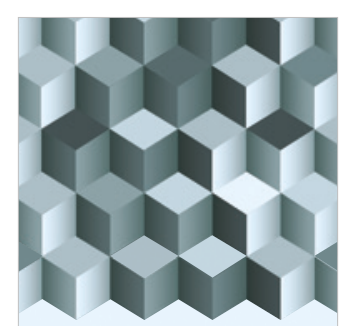

Journal of

Function Spaces

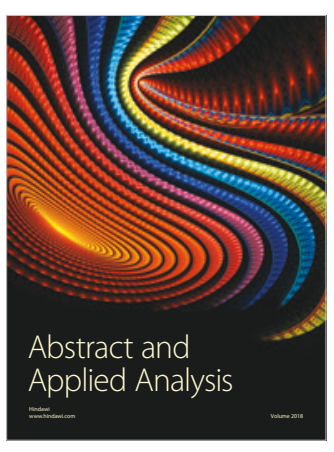

The Scientific

World Journal

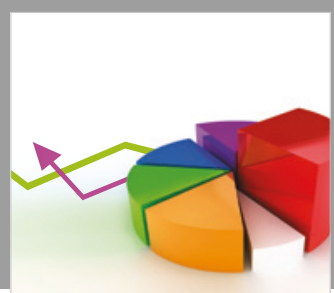

Journal of

Probability and Statistics
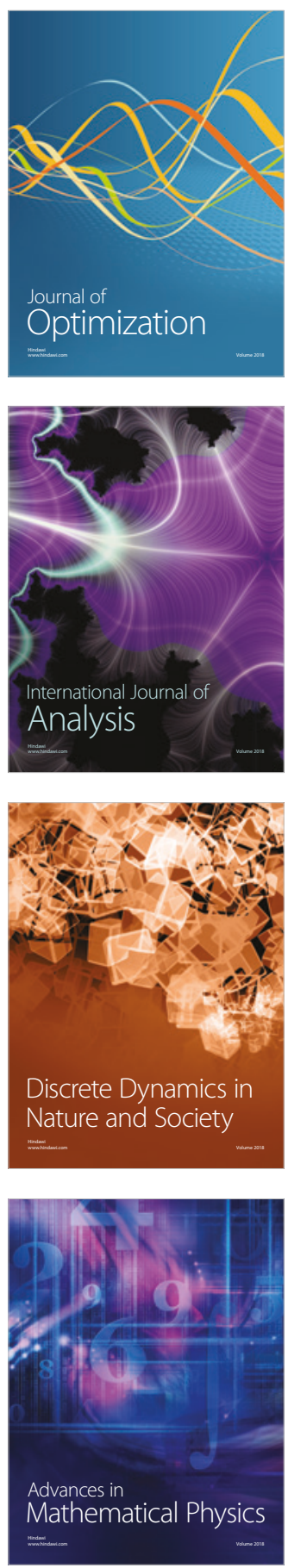